88PC-88935"QTR-8

\title{
INHIBITION OF RETROGRESSIVE REACTIONS
}

IN COAL/PETROLEUM CO.PROCESSING

\section{QUARTERLY TECHNICAL PROGRESS REPORT}

Reporting period: June 1 - August 31, 1990.

\author{
Harold Schobert \\ Jasna Tomic \\ David Moyer \\ Jessel McConnie
}

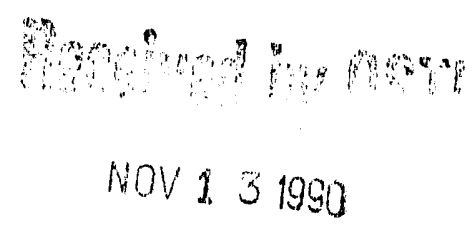

September 1990

Contract No. DE-FG22-88PC88935

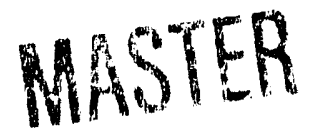

DSTRIBUTION OF THIS DOCUMENT IS UNLIM! 
DOE/PC/ $88935--\mathrm{T} 7$

DE91 002474

TABLE OF CONTENTS

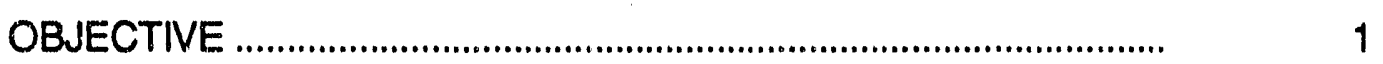

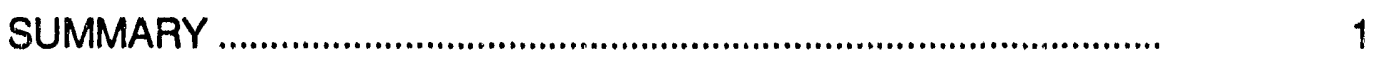

TASK 1: SELECTION OF FEEDSTOCK …………….....................

TASK 2: IDENTIFICATION OF SOLVATION AND

DISPERSION RELATIONSHIPS ……............................... 2

LITERATURE CITED ………….....................................................

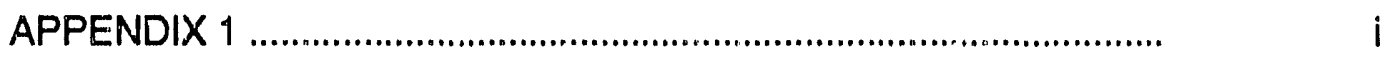

APPENDIX 2 …....................................................................... i

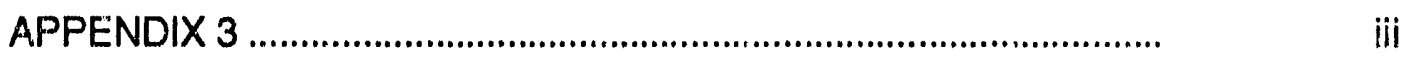


The overall objective of this project is to develop a fundamental understanding of the reactions occurring at the onset of coke formation during the co-processing of coals with petroleum residua. The specific objectives include examination of chemical components, or groups of cornponents, in coals and petroleum feedstocks to quantify and rank the effects of these components in retarding or enhancement of coke formation. The work involves bench scale reactions in microautoclaves, supplemented by studies of the carbonaceous residues by such techniques as diffuse reflectance Fourier transform infrared spectroscopy and $13 \mathrm{C}$ nuclear magnetic resonance spectrometry.

During this reporting period microautoclave testing of mixtures of model compounds and coal was concluded. In addition mixtures of coals and petroleum feedstocks were reacted under the same reaction conditions as used for the model compounds experiments. The petroleum resids were also independently tested in absence of coal. For a set of coal/resid feedstock pairs tests were performed in both horizontal and vertical microautoclaves in order to compare the mixing properties of these two different designs.

\section{SUMMARY}

The focus of the work during this reporting period was the solvation and dispersion relationship involving the reactions of coals with five model compounds: eicosane, 1-phenyldodecane, 1,4-diisopropylbenzene, durene, and pyrene and two petroleum vacuum resids, namely FHC-571 and FHC-470. Reactions were performed under a hydrogen atmosphere and were compared to the results of the reactions when nitrogen was used. Coal conversions for the model compound reactions and the co-processing reactions were compared. The influence of temperature, gas atmosphere, and feedstock on the percent of coal conversion were examined. The influence of mass transfer was examined using vertical and horizontal microautoclaves.for a selected number of experiments. The solid residue was analyzed by ${ }^{13} \mathrm{C}$ NMR and these spectra were compared to the baseline $13 \mathrm{C}$ NMR spectra of the coal. 


\section{IASK 1: SELECTION OF FEEDSTOCK}

As reported earlier this Task is essentially finished. Some additional resid samples will be acquired at a later data when the process chemistry now being developed will allow us to specify in advance a "good" and "poor" resid.

\section{IASK2: IDENTIFICATION OF SOLVATION AND DISPERSION REALTIONSHIPS}

\section{Model Compound Reactions}

During this reporting period, the five project coals were reacted with the five model compounds under a hydrogen atmosphere (Appendix 1). The results of the reactions under a nitrogen atmosphere were previously reported [1]. The reaction temperatures were $350^{\circ}, 400^{\circ}$, and $450^{\circ} \mathrm{C}$, and the starting pressure was 3.5 MPa. Coal conversion is defined on the basis of yield of THFinsolubles as:

$$
\text { Conv\% }=\left[1-\frac{\text { THFinsoluble }}{\text { Wt.coal (daf) }}\right] \times 100
$$

\section{Gas atmosphere effect}

There does not seem to be a consistent influence of the gas atmosphere on coal conversion in the model compound reactions. Comparisons of coal conversions under a nitrogen and hydrogen atmosphere at a given temperature are shown in Figures 1-15. Under the given conditions of these tests, namely 3.5 $\mathrm{MPa}$ of nitrogen or hydrogen, the differences in degree of coal conversions are not significant. It is generally expected that the conversions would increase in the presence of hydrogen gas, but under the given reaction conditions the effect of the chernical nature of the coal and the model compound seem to override the effects of the gas atmosphere. At the lowest reaction temperature of $350^{\circ} \mathrm{C}$ the coal conversions are generally higher when hydrogen gas is present for all model compounds except pyrene. In the reactions of pyrene and coal comparably high coal conversions were achieved under a nitrogen atmosphere and in some cases even higher than under a hydrogen atmosphere. Orice again, as mentioned in the earlier report [1], pyrence exhibits significantly different behavior than any of the other four model compounds. 
Temperature effect

The reaction temperature has a different effect on the conversion of the five coals. Figures 16-20 show the coal conversion with different feedstock and reaction temperatures with hydrogen gas overpressure, and Figures 21-25 show the respective coal conversions under a nitrogen atmosphere. For the two lower rank coals used in this project, subbituminous B (PSOC 1488) and hvC bituminous (PSOC 1498) the coal conversion increases with increasing temperature of reaction. The exceptions are reactions with pyrene when the maximum coal conversions are achieved at $400^{\circ} \mathrm{C}$. For the three remaining project coals (hvB and hvA bituminous) the highest coal conversions are obtained at $400^{\circ} \mathrm{C}$. This pattern is observed when nitrogen or hydrogen overpressure is used. The reason for this behavior probably is that the the higher rank project coals all have their temperature of maximum fluidity above $400^{\circ} \mathrm{C}$ while the two lower rank coals have $\mathrm{FSI}$ 's of 0 and 0.5 respectively.

\section{Reactions with Petroleum Resids}

Thermal stability tests on the two petroleum resids were completed. The yield of THF-insolubles was observed in reactions under a nitrogen atmosphere and under a hydrogen atmosphere. The results in Appendix 2. show that neither of the vacuum feed resids, FHC-571 and FHC-470 produced a significant amount of insolubles at $350^{\circ}$ or $400^{\circ}$ reaction temperatures. The yield of insolubles increases at $450^{\circ} \mathrm{C}$. In the case of FHC-571 the maximum yield insoluble is $3 \%$ of the total weight of resid. For the sample FHC-470 the yield insoluble is greater, around $15 \%$ of the total weight of the resid. The gas atmosphere does not seem to influence the production cf insolubles from these two petroleum resid feedstock.

The two resids were reacted with the five project coals under the same reaction conditions as the model compound reactions. A nominal charge of $2.5 \mathrm{~g}$ of coal and approximately $5 \mathrm{~g}$ of resid were reacted in microautoclaves. Due to the high viscosity of the petroleum resids, the loadings varied anywhere from 4.5 to $6 \mathrm{~g}$. Reactions were conducted using nitrogen and hydrogen overpressure of $3.5 \mathrm{MPa}$ at the beginning of the reaction. The results in Appendix 2 show that the amount of insolubles formed is the smallest at reaction temperature $400^{\circ} \mathrm{C}$. On the other hand, at temperature $450^{\circ} \mathrm{C}$ the yield of insolubles dramatically increases. 
Comparing these results to the previous thermal stability tests of the coal alone and resid alone, it is obvious that none of the project coals or petroleum resids produced this high yield of insolubles. The interactions between the coal particles and petroleum resids at the highest reaction temperature seem to favour the retrogressive reactions and the formation of insoluble matter. The Figures $16-25$ show that coal conversion is steadily negative at reaction temperature $450^{\circ} \mathrm{C}$ in the presence of petroleum resids. On the other hand, the coal conversions in the reactions with petroleum resids at $400^{\circ} \mathrm{C}$ are in the range of those conversion achieved in the presence of pyrene. It was previously noted that of all the model compounds tested in this project pyrene acted most favorably in terms of minimizing the production of THF-insolubles. The results indicate that petroleum resids are as good solvents for coal particles as pyrene for reaction temperatures less than $450^{\circ} \mathrm{C}$.

For most of the coals used in reactions with petroleum resids, higher conversions were obtained in the presence of hydrogen. The exception is the high volatile A, PSOC 1448 coal when reactions with nitrogen overpressure resulted in higher coal conversion.

\section{Microreactor Design Comparison Reaction:;}

A selected number of coal-model r,ompound pairs were reacted under same reaction conditions (pressure and temperature) in a vertical tubing bomb reactor normally used in this project and a horizontal one of the same volume. The reason for this is to test the mixing properties and mass transfer effects of these two different designs, and to evaluate the effect of the microreactor design on the yield of insoluble matter hence, coal conversion. For this purpose one coal and one reaction temperature were chosen and were reacted with eicosane, diisopropylbenzene and, pyrene in a nitrogen and hydrogen atmosphere. The table with the collected data for these experiments is in Appendix 1. The yield of insolubles when horizontal microreactors are used are lower by $2-4 \%$ compared to the experiments with the vertical design. This result seems to be in agreement with the results reported by Rhee et al [2]. that the horizontal oriented microreactors have advantage over the vertical oriented microreactors in terms of mixing properties in the absence of agitator balls. For the scope of this project though, these differences are not that significant and under the reaction conditions used here the design of the microreactor does not seem to have a great effect. 
Characterization of Solids Products

A number of solid residue were analyzed by ${ }^{13} \mathrm{C}$ NMR. The instrument used was a Chemagnetics MS-100. Appendix 3. contains the spectra of the insoluble residue of thermal reactions of PSOC 1488 under nitrogen and hydrogen at various temperatures and a spectra of a residue of unreacted coal after extraction with THF. Most obvious is the expected decrease in the aliphatic region and the accompanying increase in the aromatic region. This change is more apparent when the reaction temperatures is increased from $400^{\circ} \mathrm{C}$ to $450^{\circ} \mathrm{C}$ and less when the increase is from $350^{\circ} \mathrm{C}$ to $400^{\circ} \mathrm{C}$. Similar observations were previously reported [1] from the information gained by comparing the DRIFT spectra. 


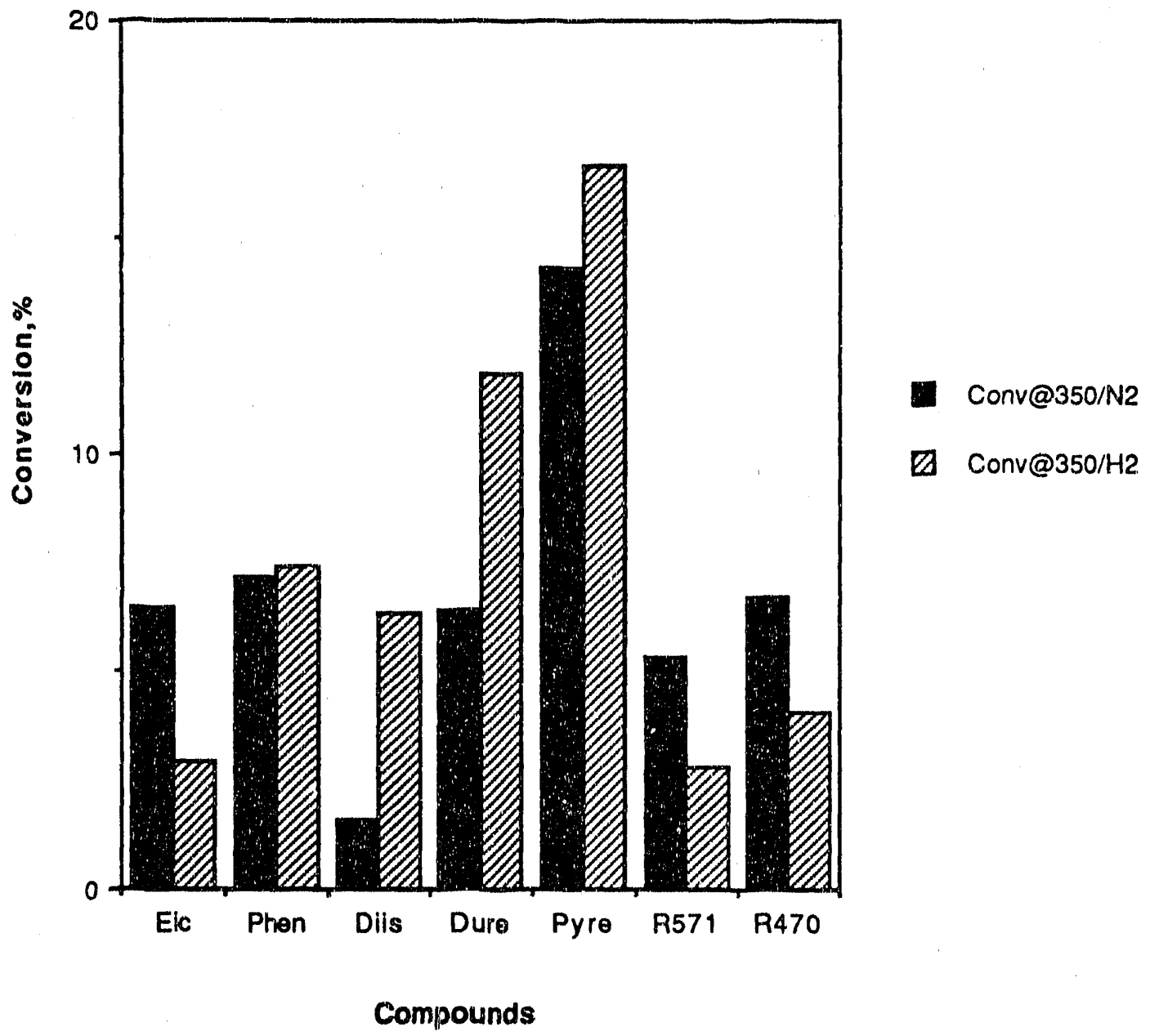

Figure 1. Conversion for PSOC1448 under N2 and $\mathrm{H} 2$ at $350^{\circ} \mathrm{C}$ 


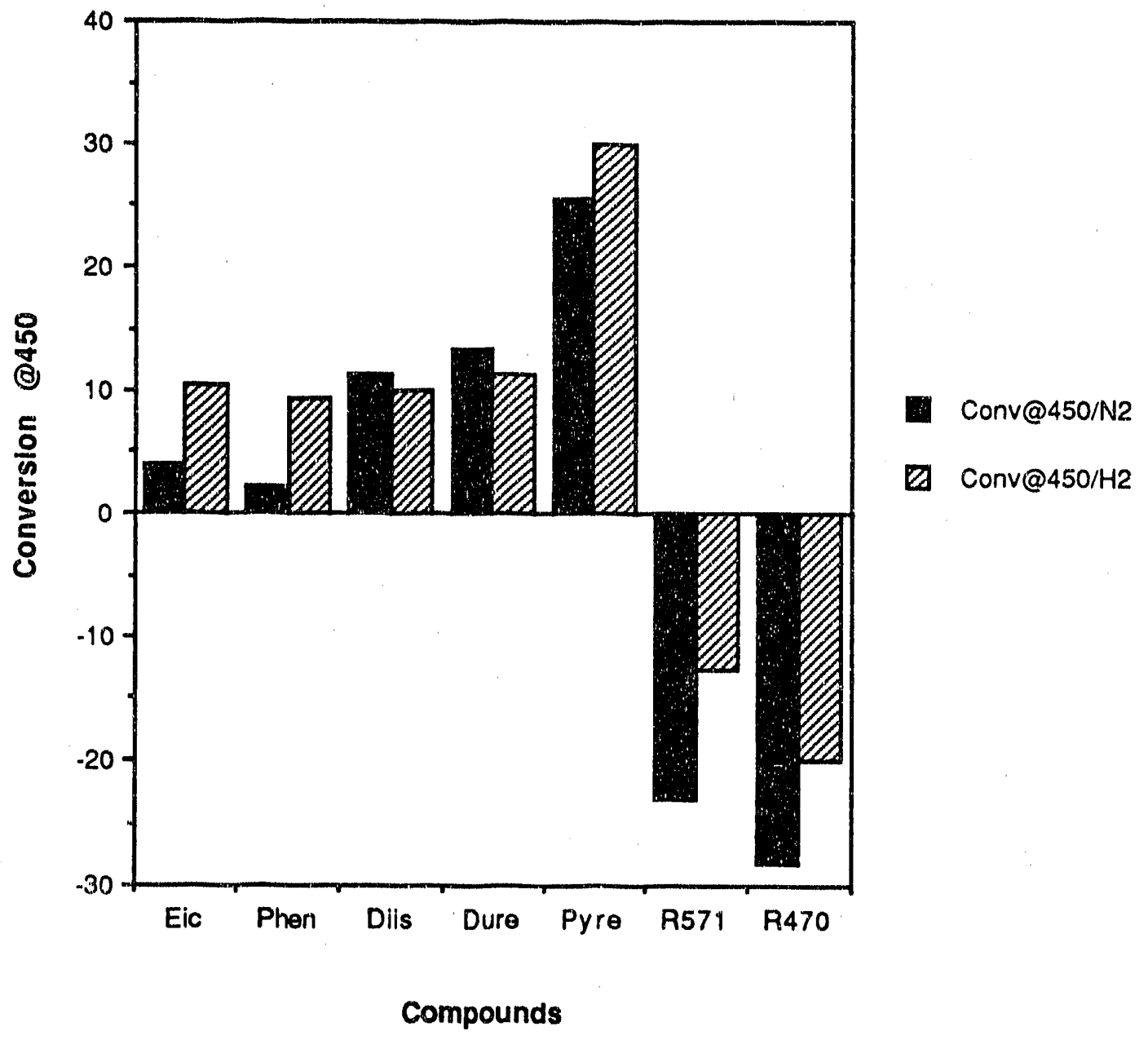

Figure 2. Conversion for PSOC 1448 under $\mathrm{N} 2$ and $\mathrm{H} 2$ at $450^{\circ} \mathrm{C}$ 


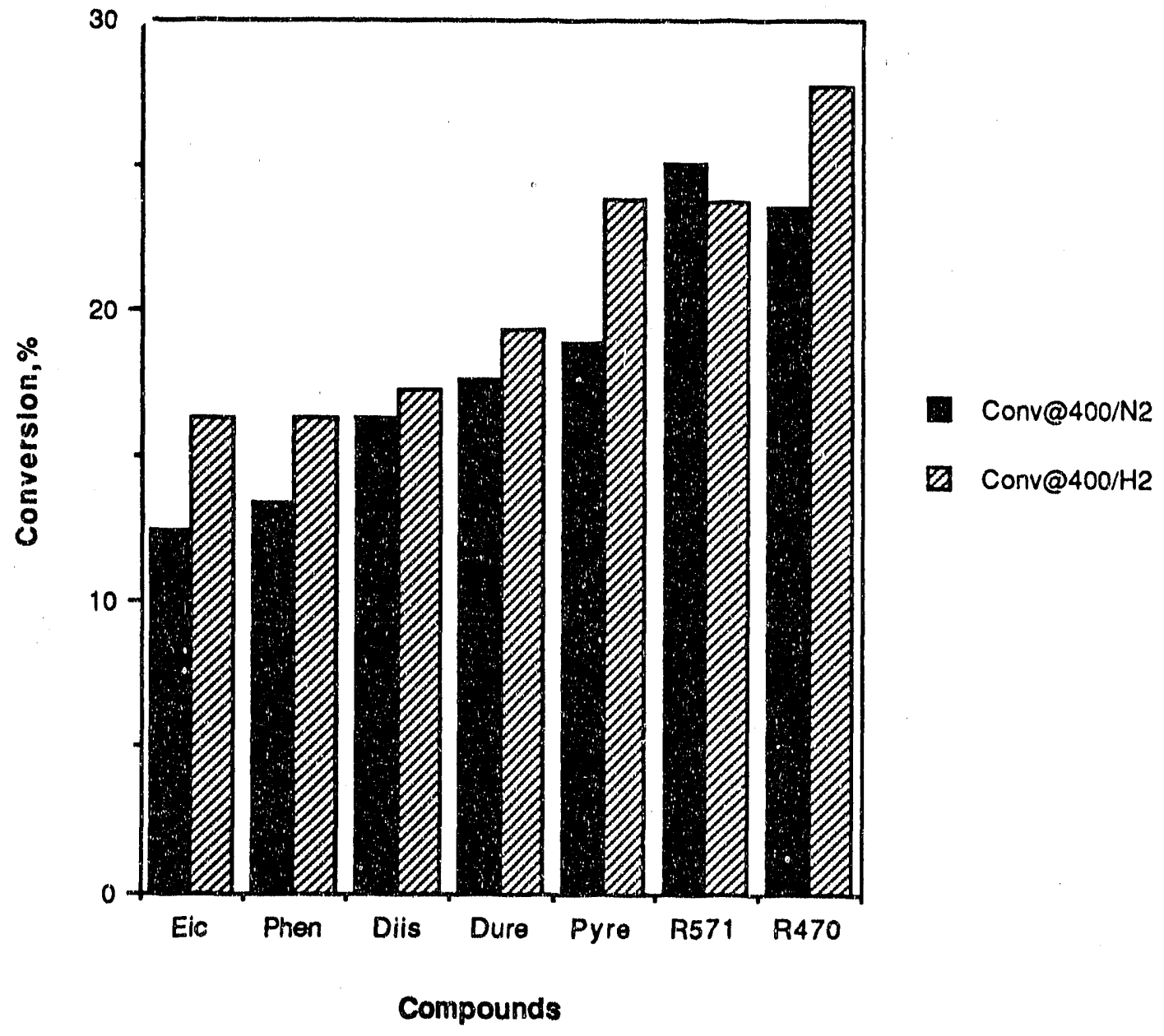

Figure 3. Conversion for PSOC1448 under N2 and H2 at $400^{\circ} \mathrm{C}$ 


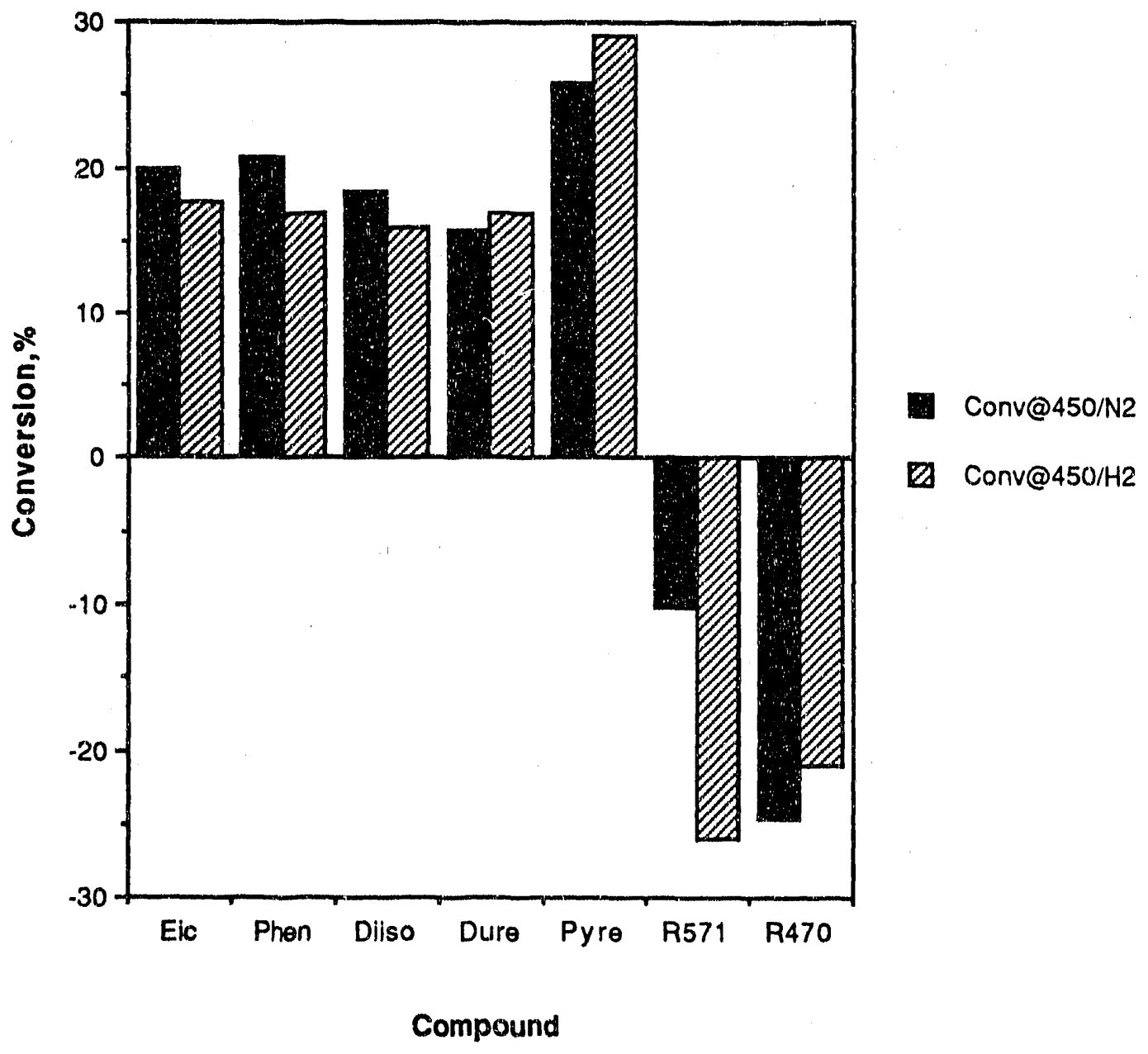

Figure 4. Conversion for PSOC1488 under $\mathrm{N} 2$ and $\mathrm{H} 2$ at $450^{\circ} \mathrm{C}$ 


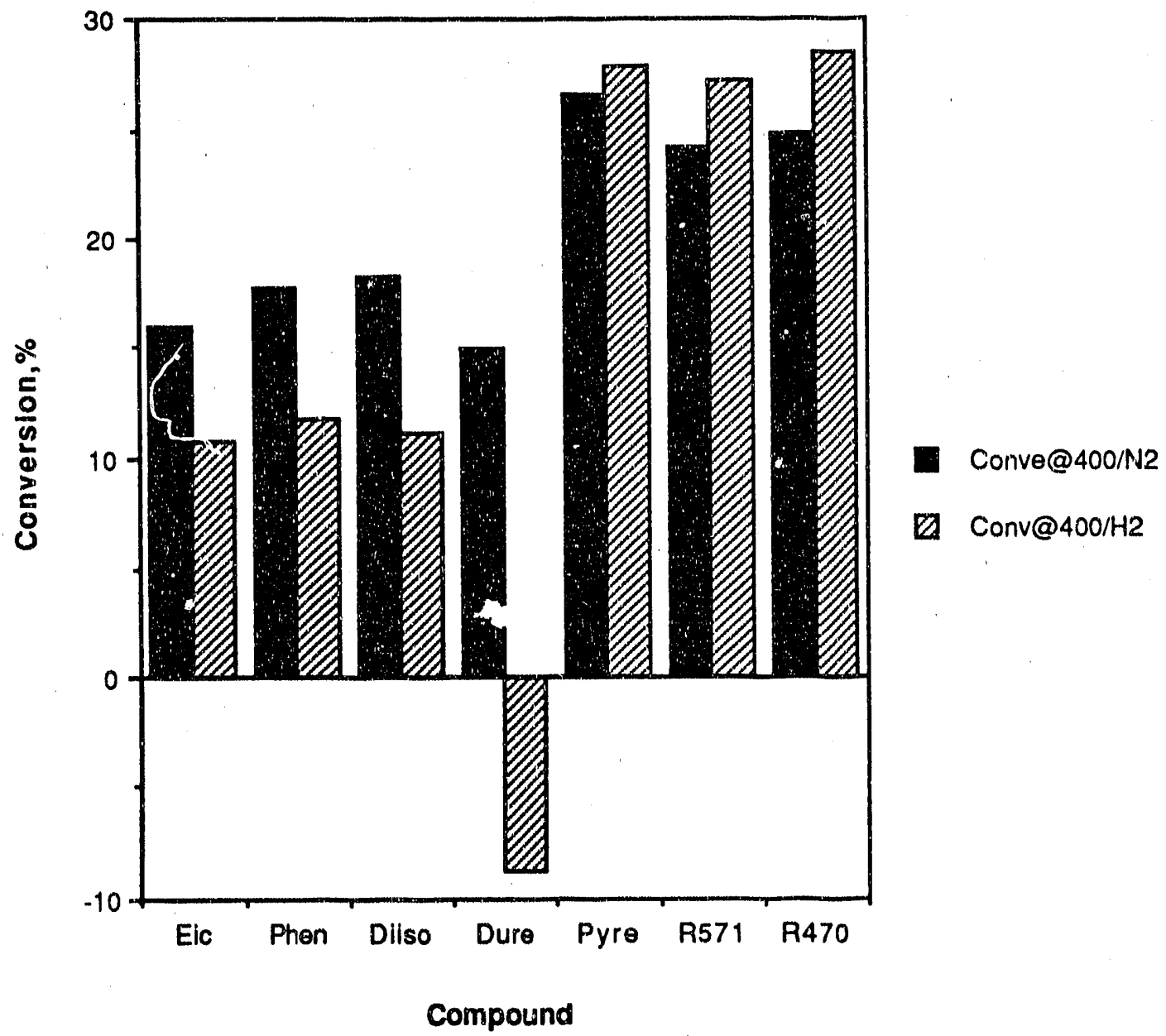

Figure 5. Conversion for PSOC1488 under N2 and $\mathrm{H} 2$ at $400^{\circ} \mathrm{C}$ 


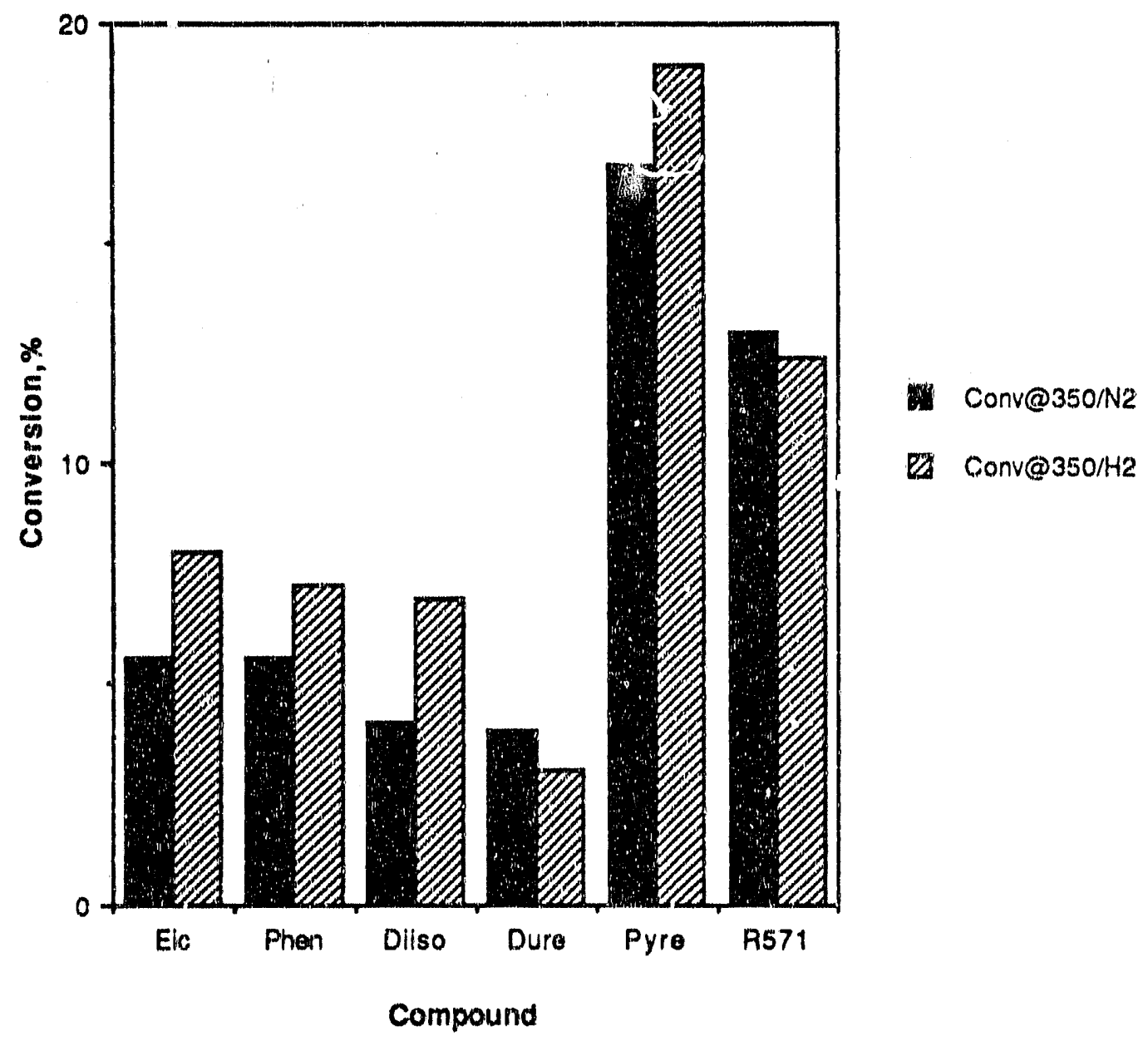

Figure 5. Conversion for PSOC1488 under N2 and $\mathrm{H} 2$ at $350^{\circ} \mathrm{C}$ 


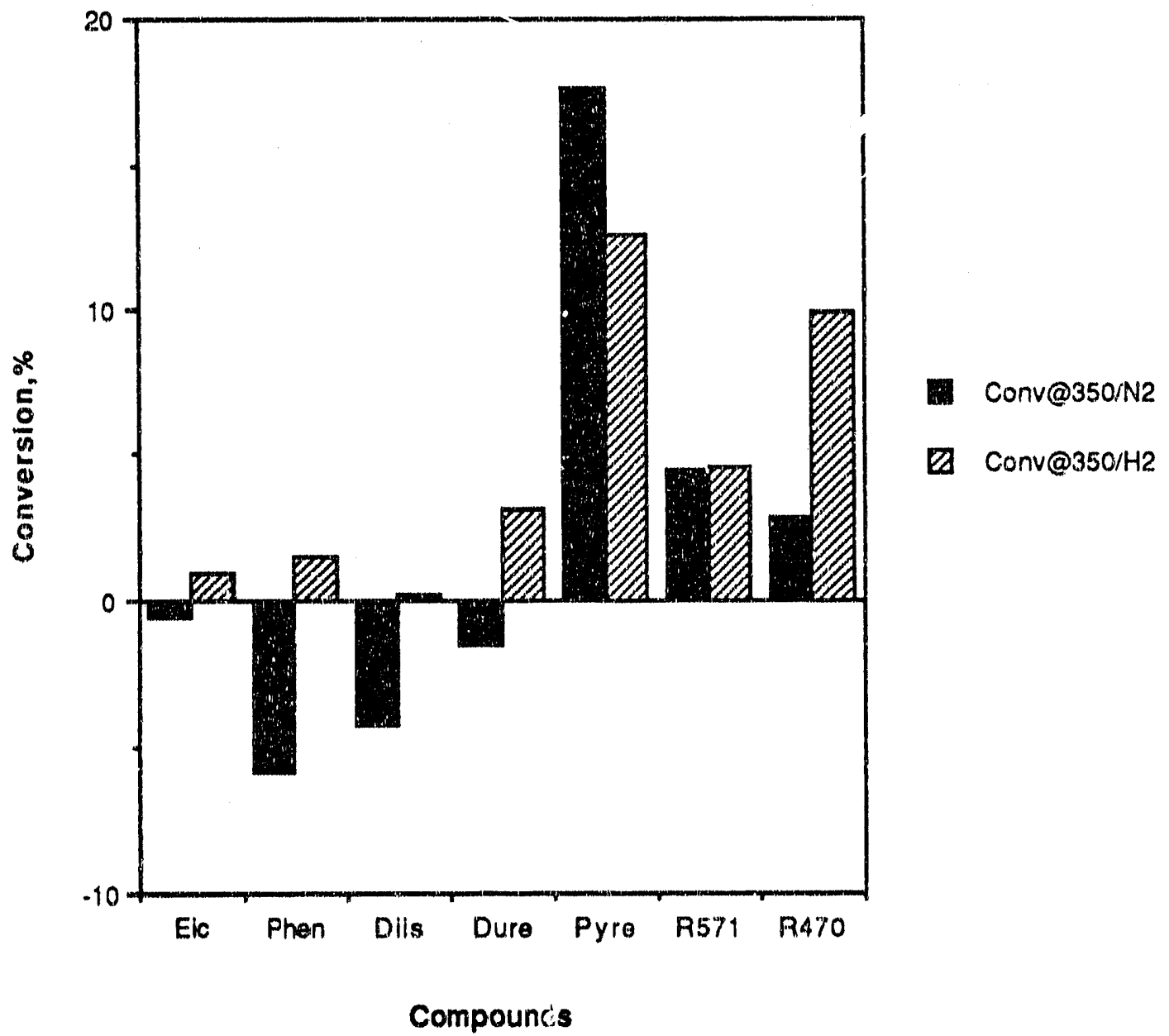

Figure 7. Conversion for PSOC1498 under $\mathrm{N} 2$ and $\mathrm{H} 2$ at $350^{\circ} \mathrm{C}$ 


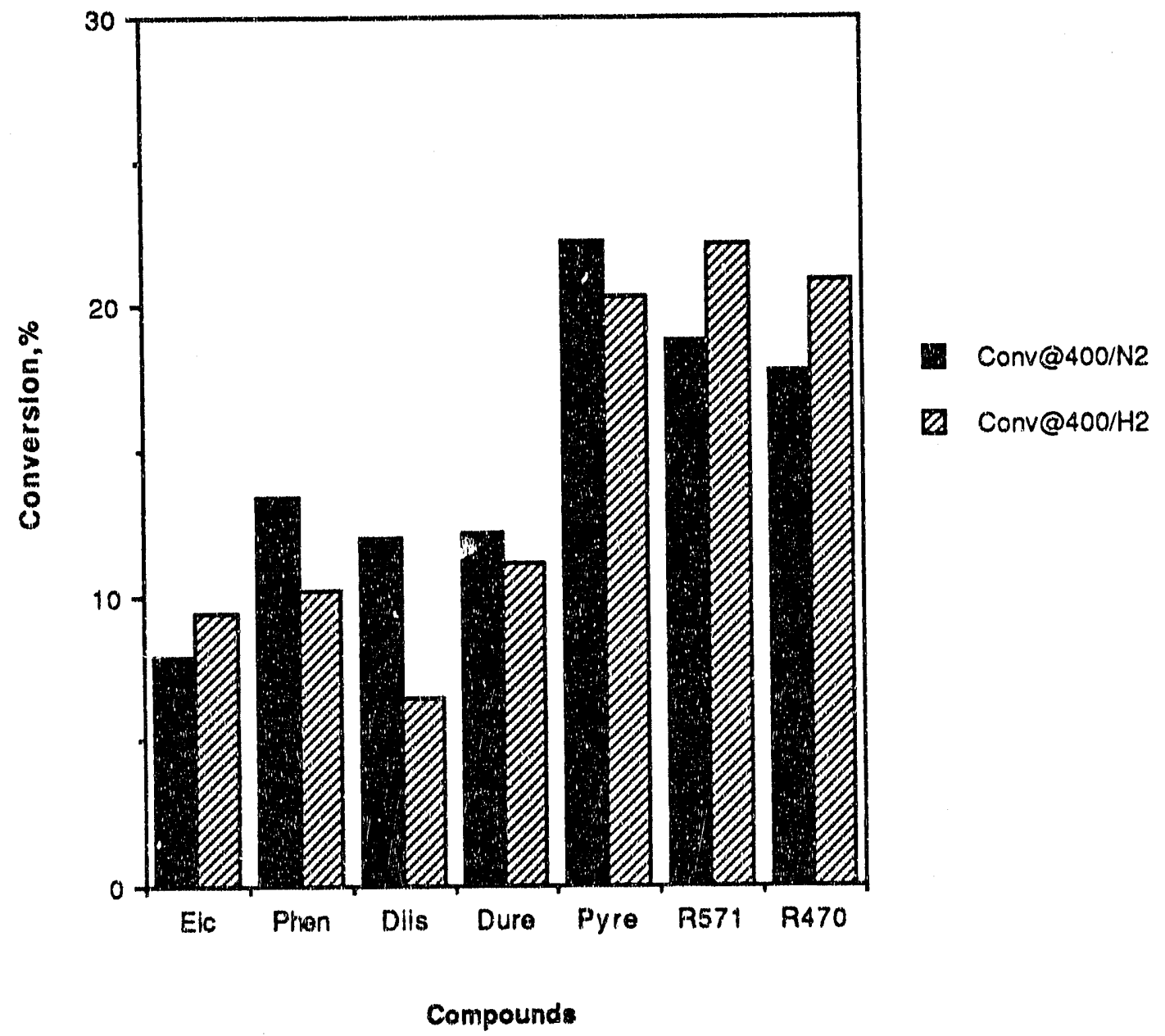

Figure 8. Conversion for PSOC1498 under N2 and $\mathrm{H} 2$ at $400^{\circ} \mathrm{C}$ 


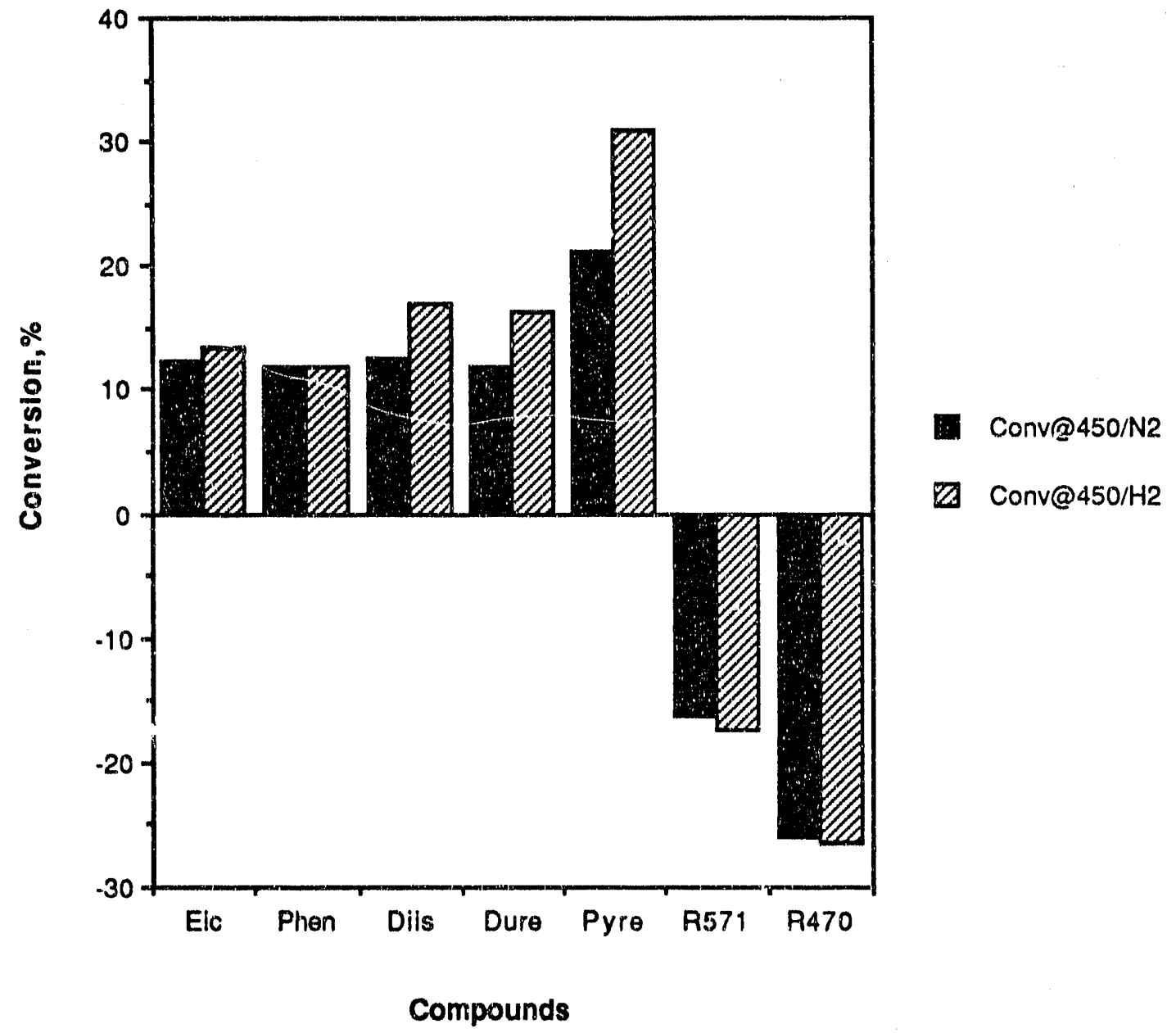

Figure 9. Conversion for PSOC1498 under N2 and H2 at $450^{\circ} \mathrm{C}$ 


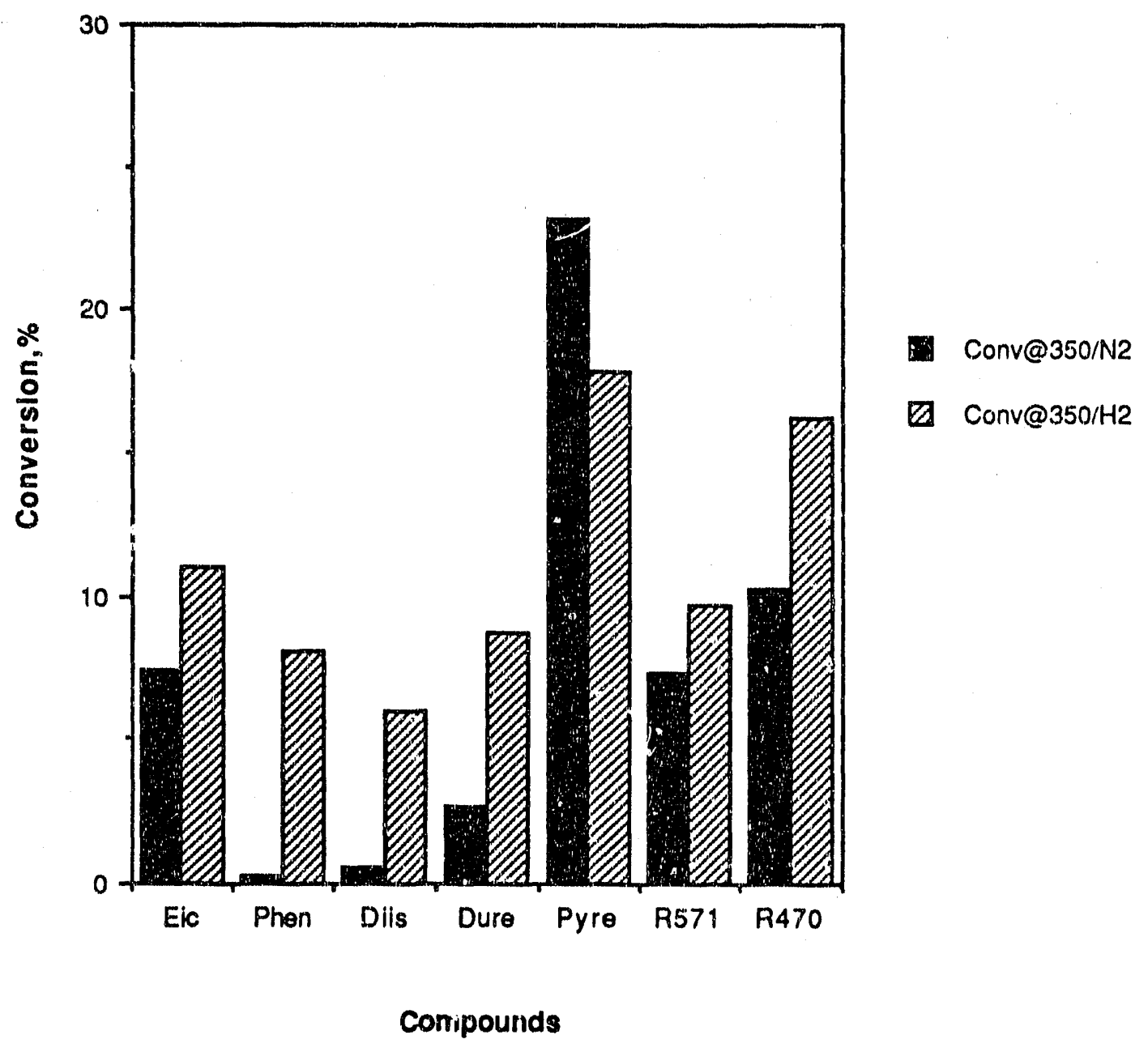

Figure 10. Conversion for PSOC1501 under N2 and H2 at $350^{\circ} \mathrm{C}$ 


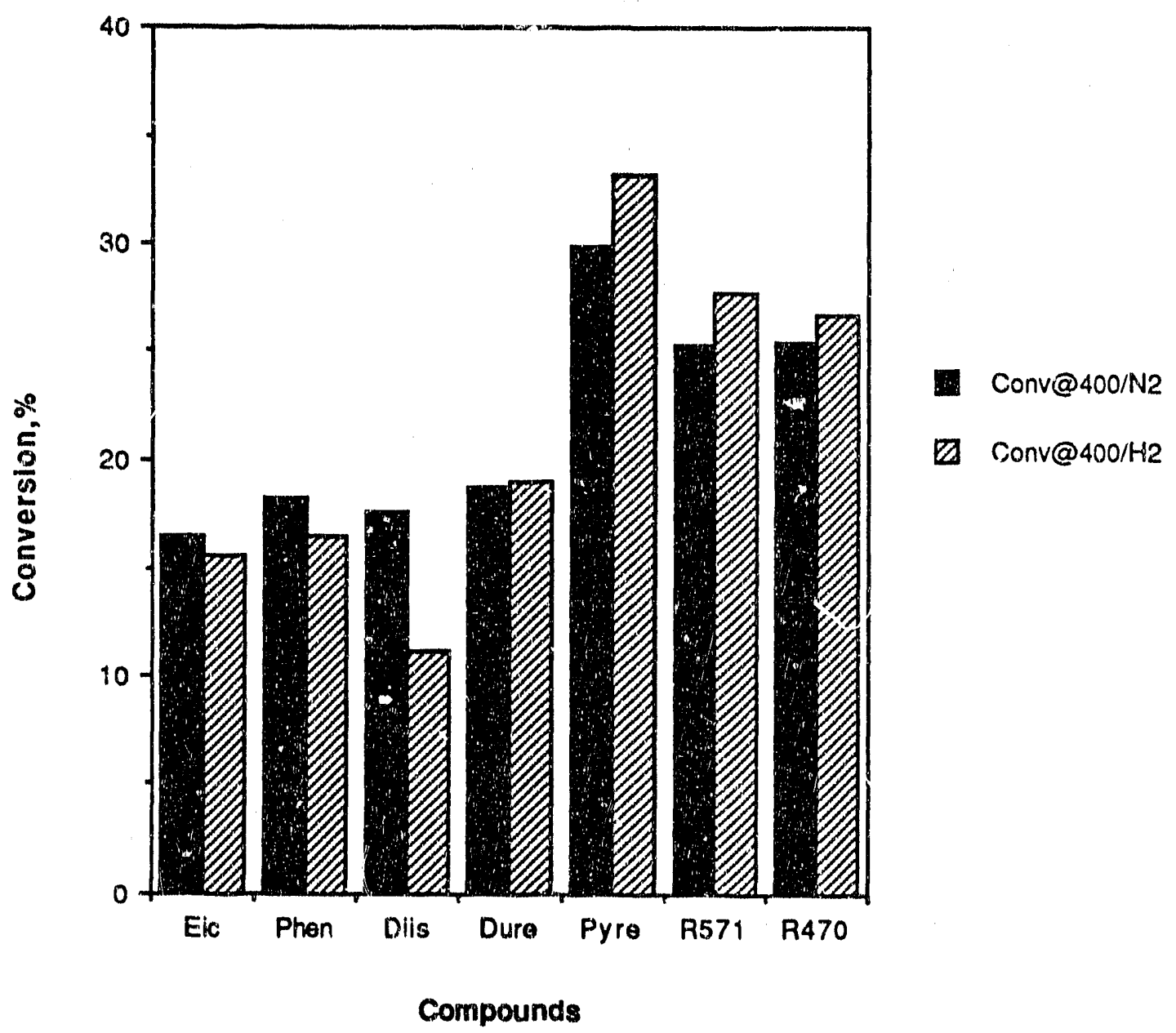

Figure 11. Conversion for PSOC1501 under $\mathrm{N} 2$ and $\mathrm{H} 2$ ai $400^{\circ} \mathrm{C}$ 


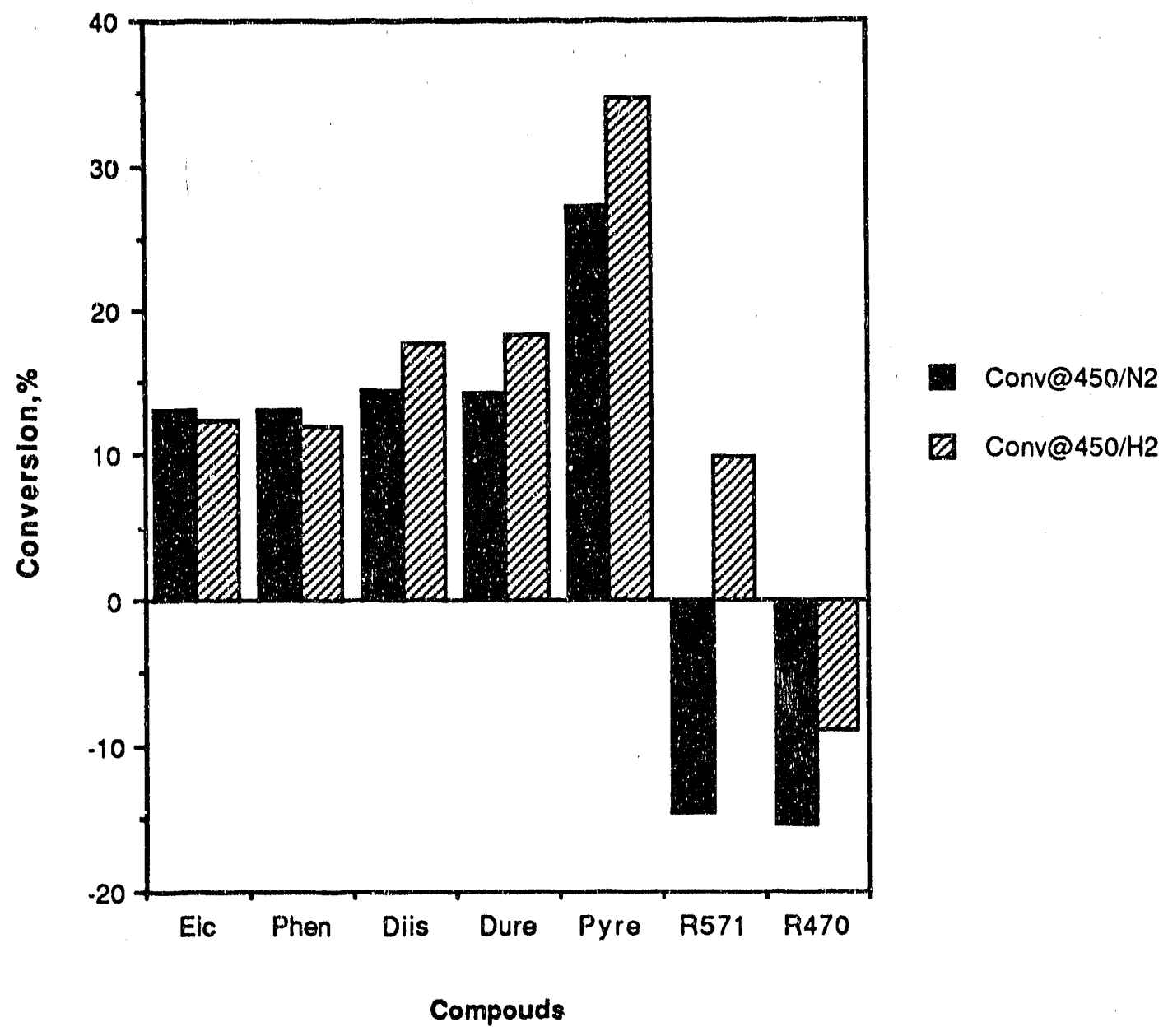

Figure 12. Conversion for PSOC1501 under N2 and $\mathrm{H} 2$ at $450^{\circ} \mathrm{C}$ 


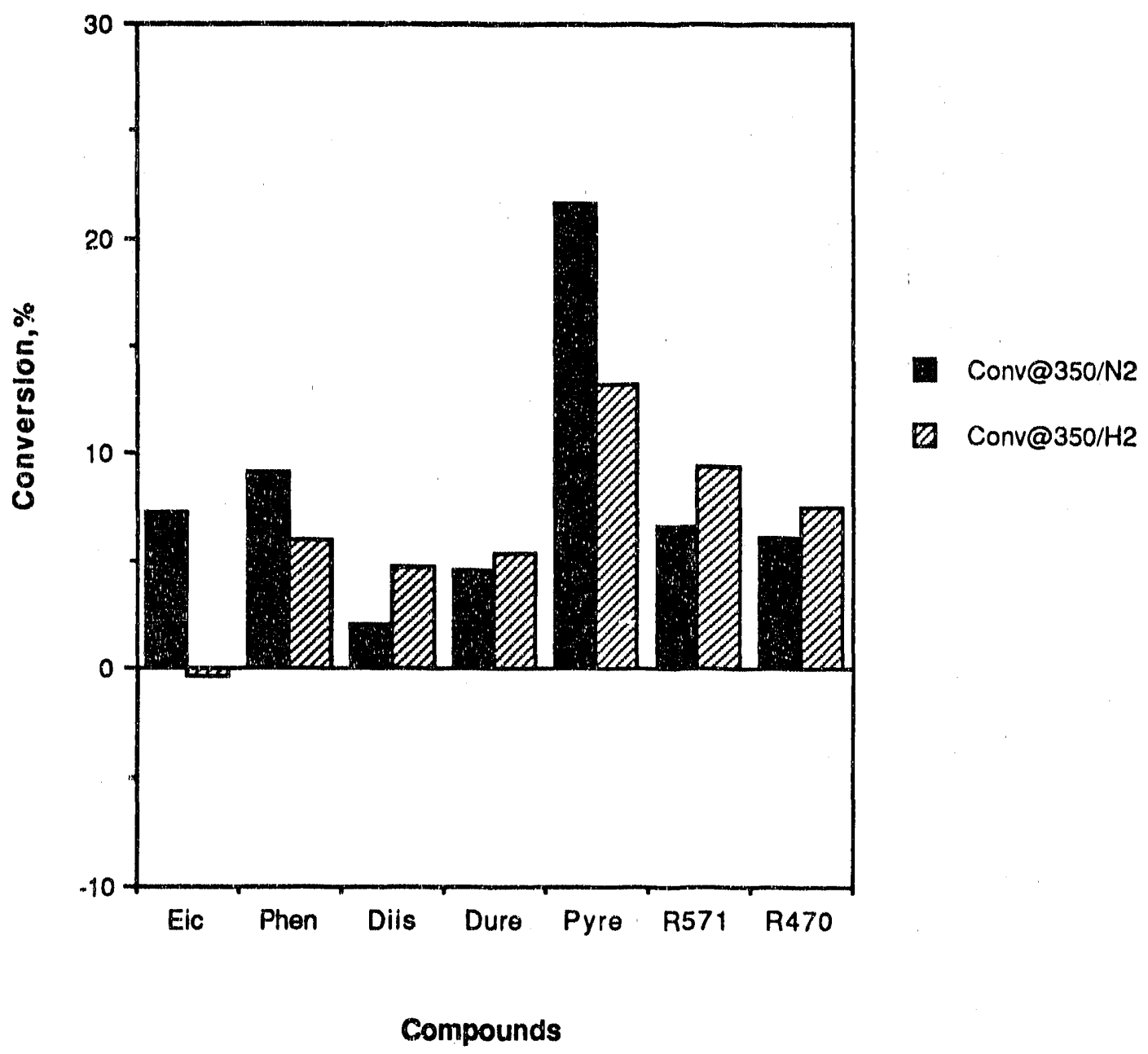

Figure 13. Conversion for PSOC1504 under N2 and H2 at $350^{\circ} \mathrm{C}$ 


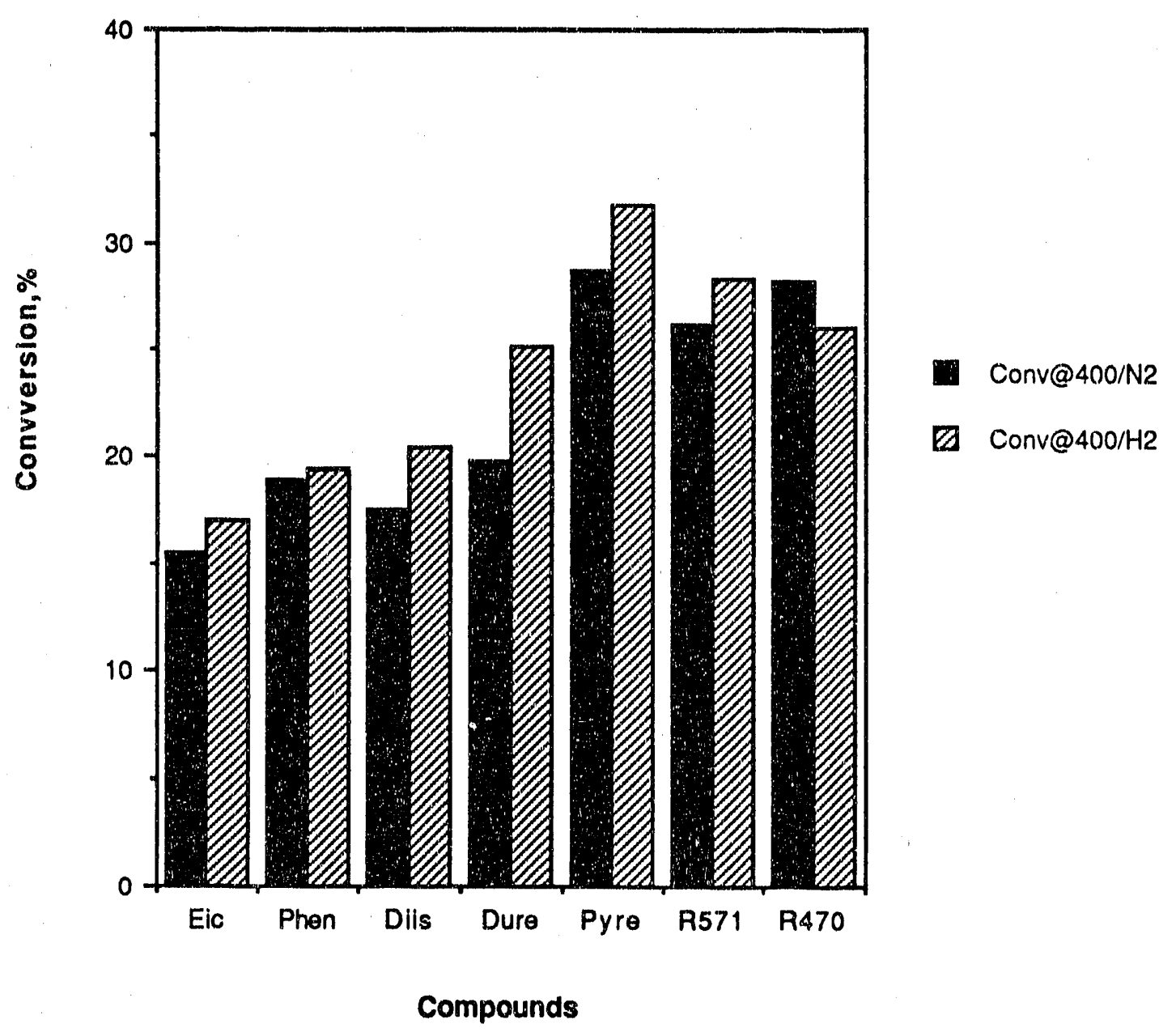

Figure 14. Conversion for PSOC1504 under $\mathrm{N} 2$ and $\mathrm{H} 2$ at $400^{\circ} \mathrm{C}$ 


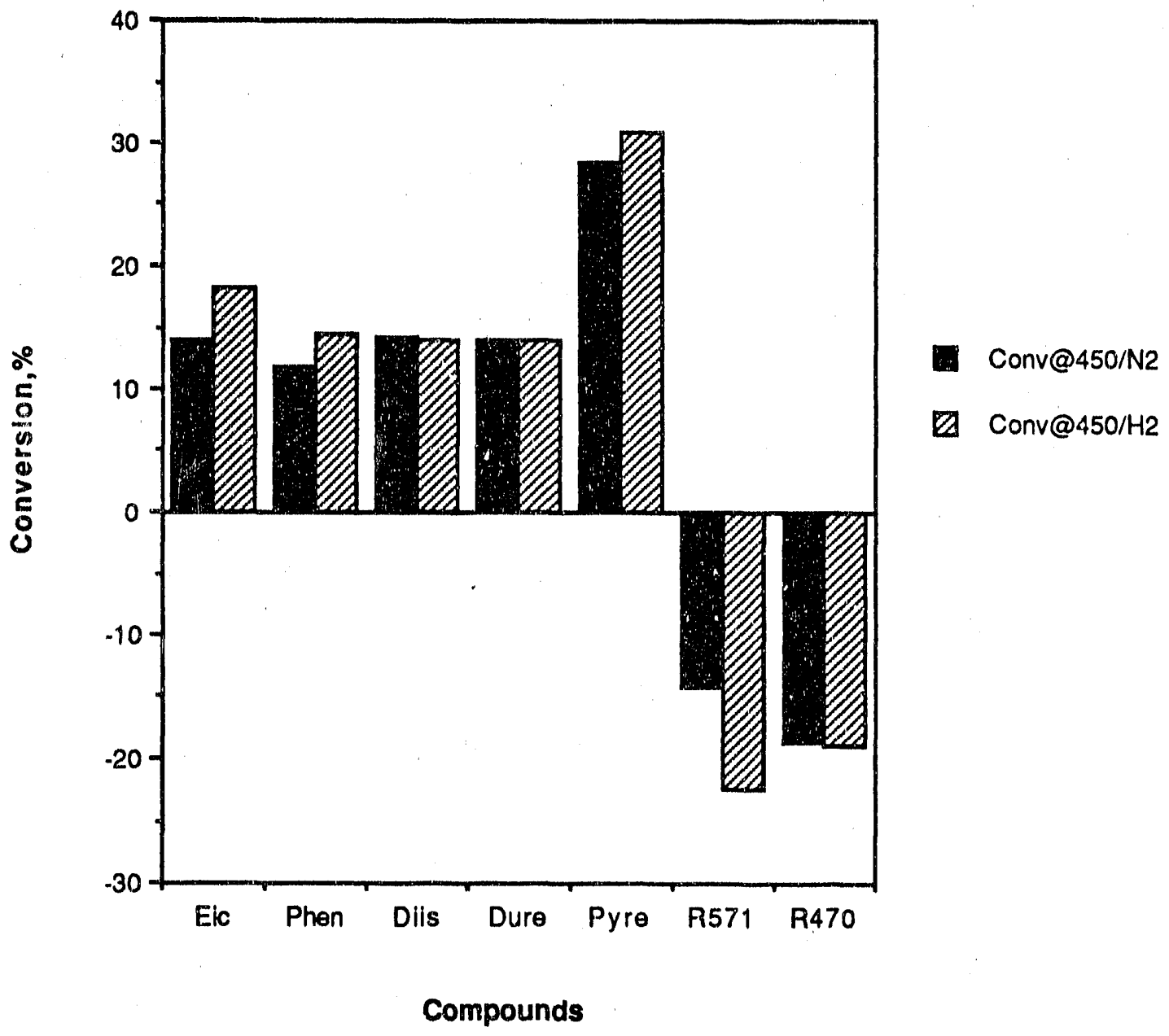

Figure 15. Conversion for PSOC1504 under $\mathrm{N} 2$ and $\mathrm{H} 2$ at $450^{\circ} \mathrm{C}$ 


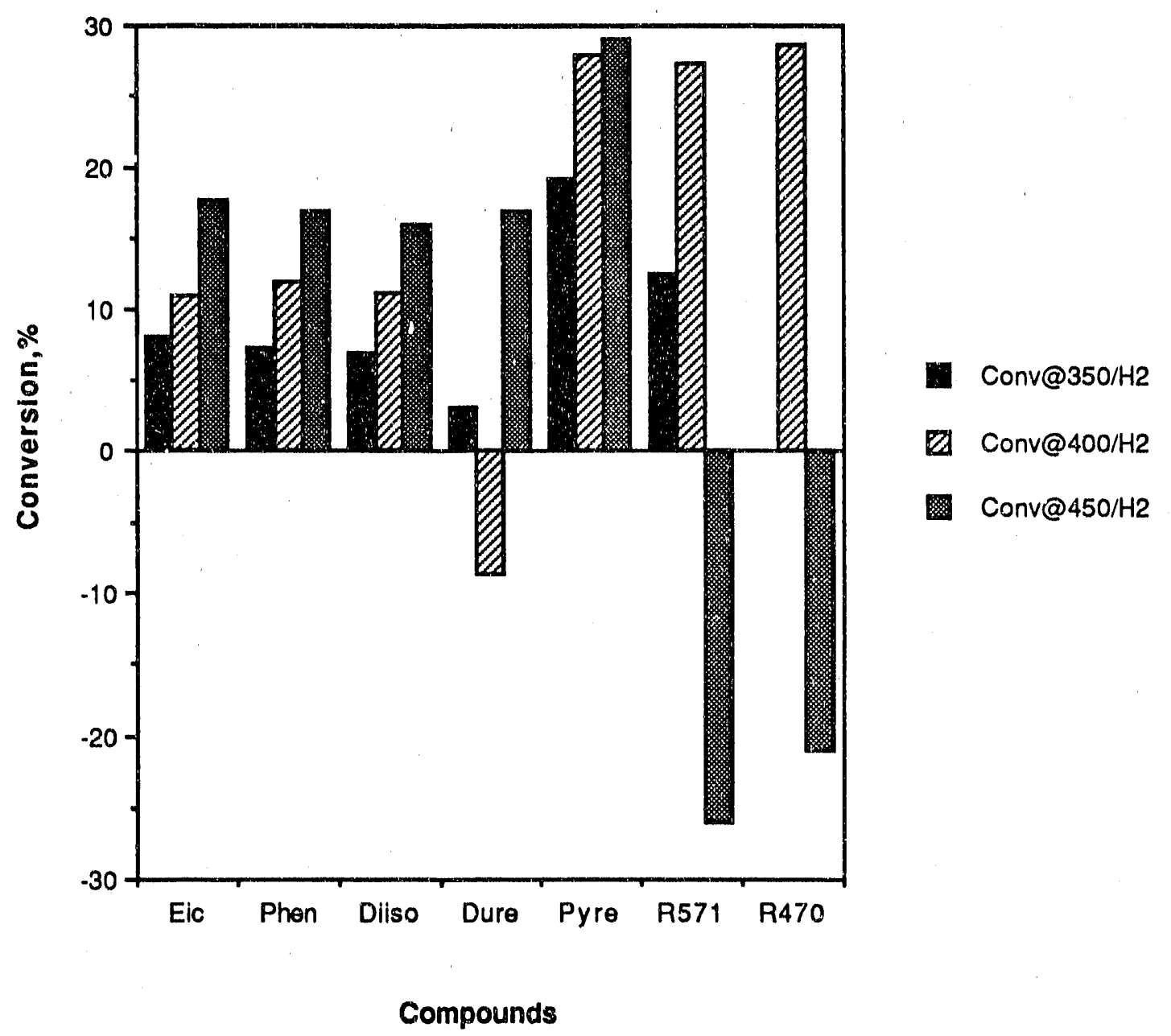

Figure 16. Conversionsfor $\mathrm{PSOC} 1488 ; \mathrm{H} 2$ at three reaction temperatures 


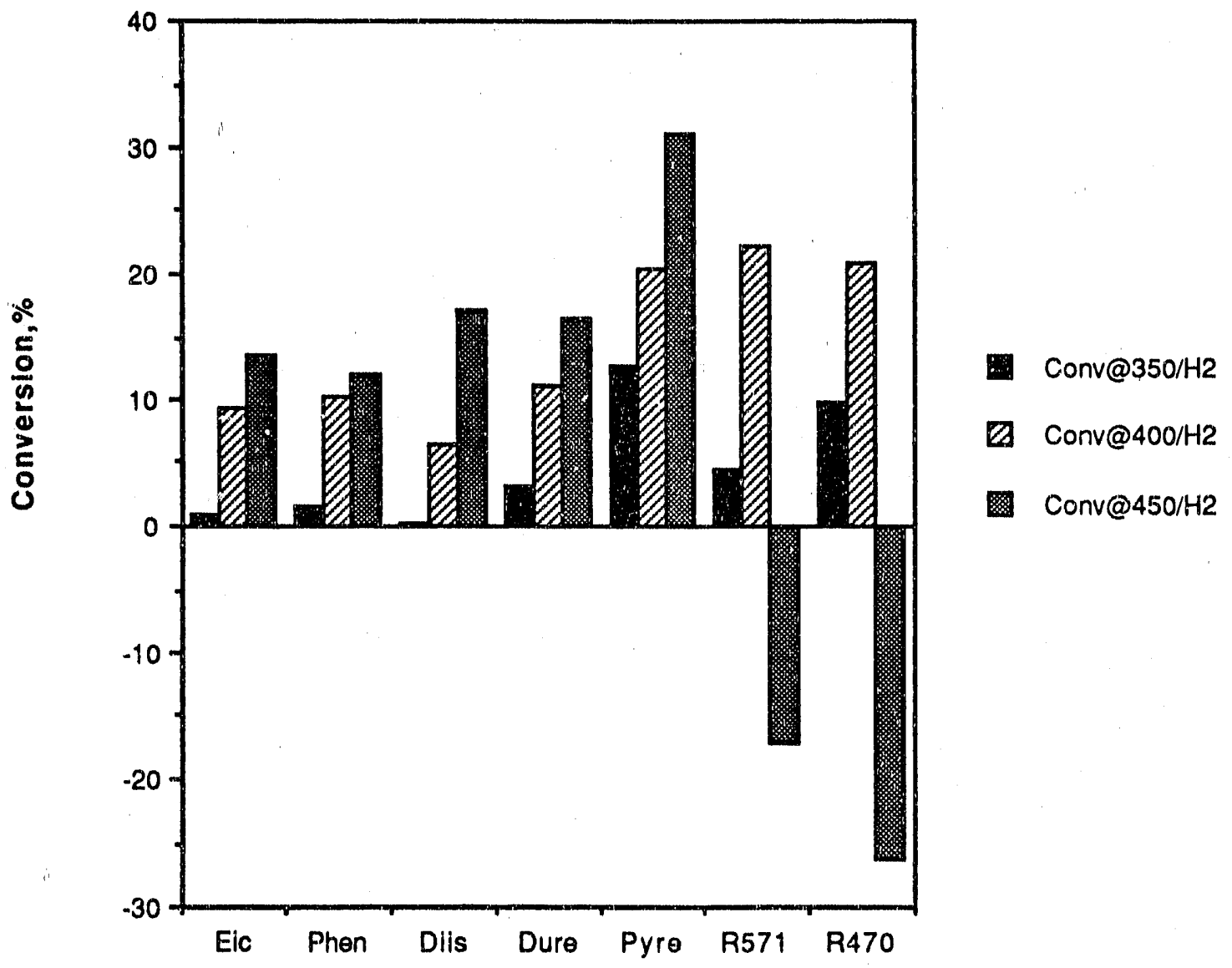

Compounds

Figure 17. Conversions for PSOC1498; $\mathrm{H} 2$ at three reaction temperatures 


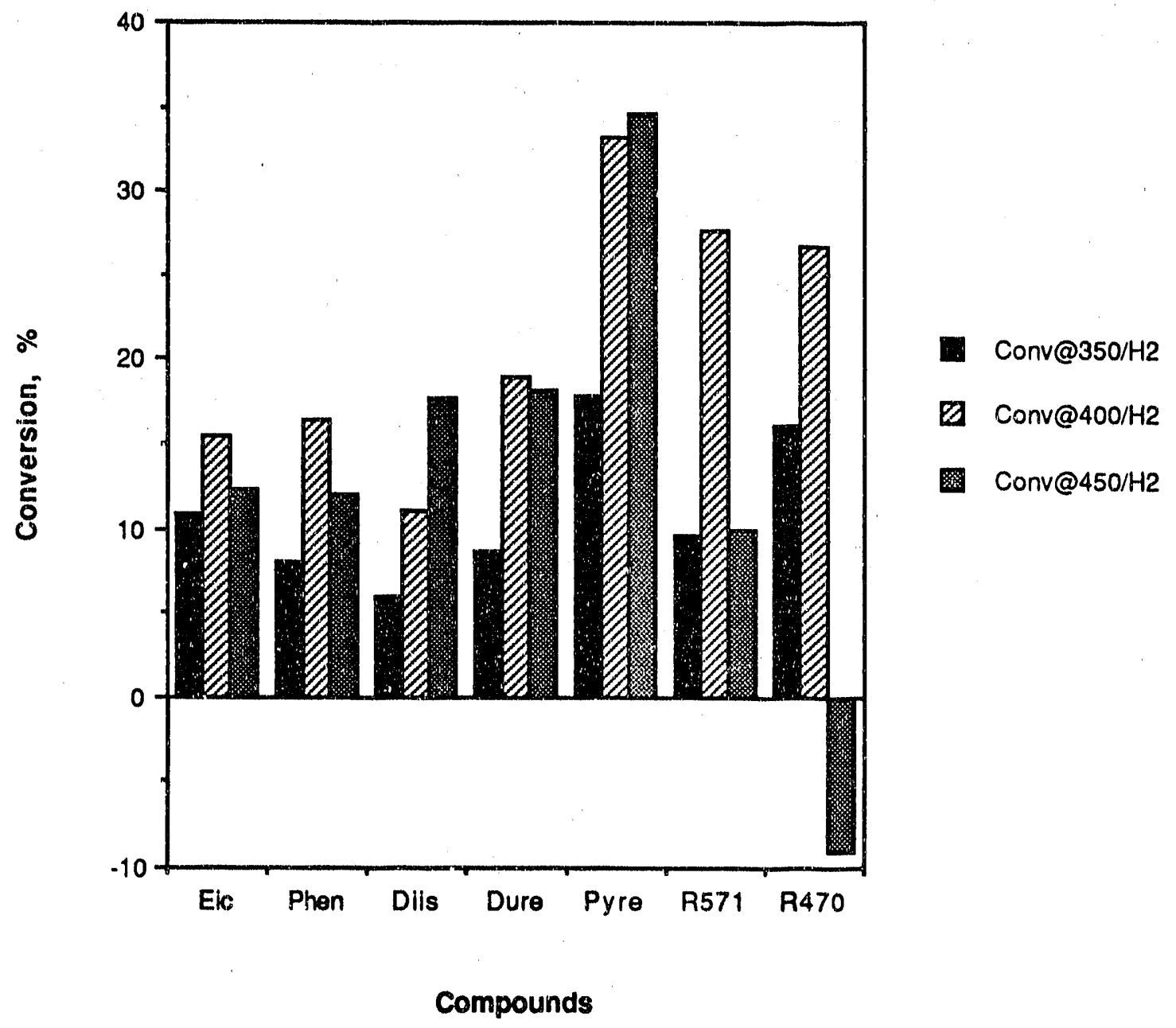

Figure 18. Conversions for PSOC1501; H2 at three reaction temperatures 


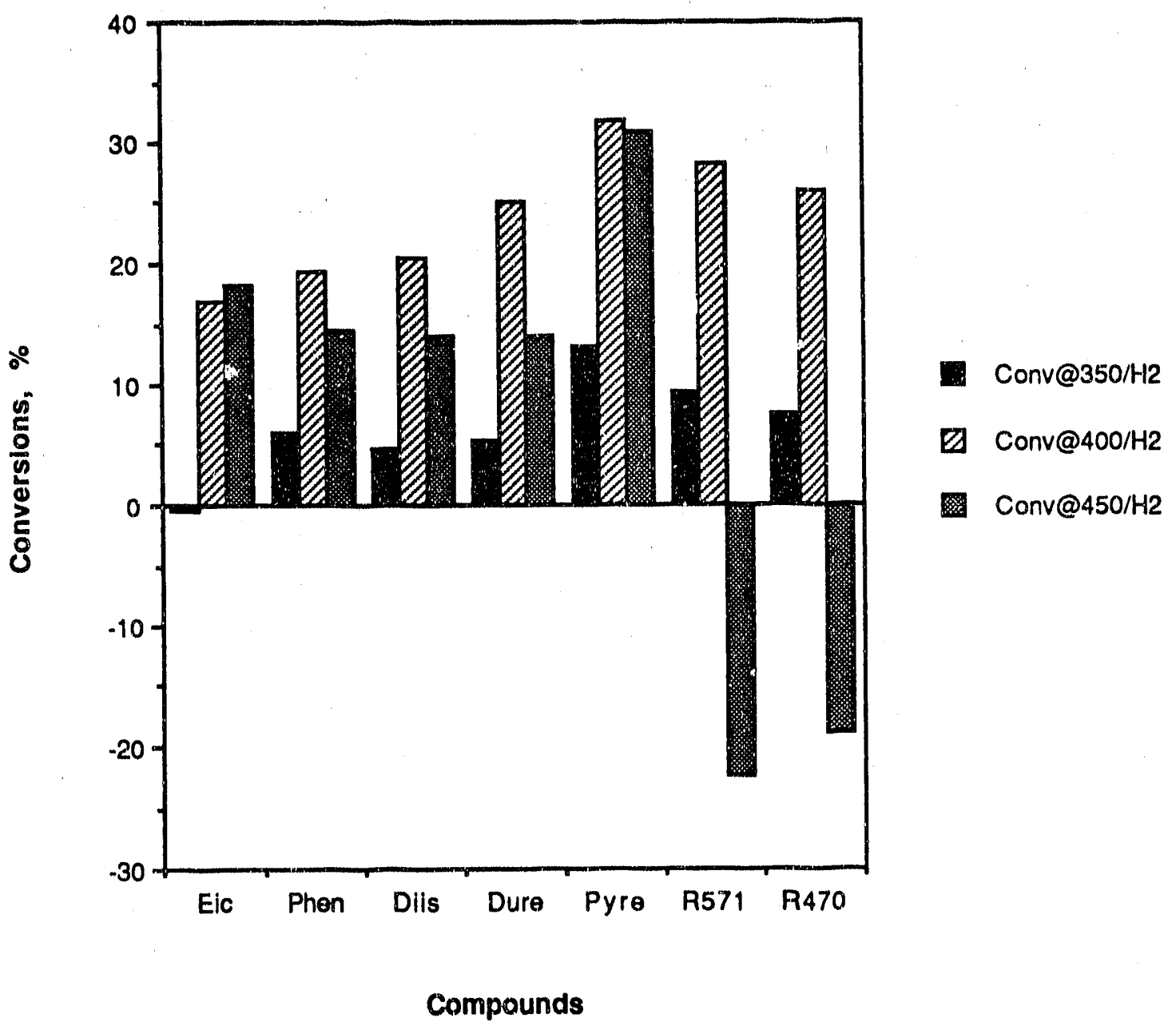

Figure 19. Conversions for PSOC1504; $\mathrm{H} 2$ at three reaction temperatures 


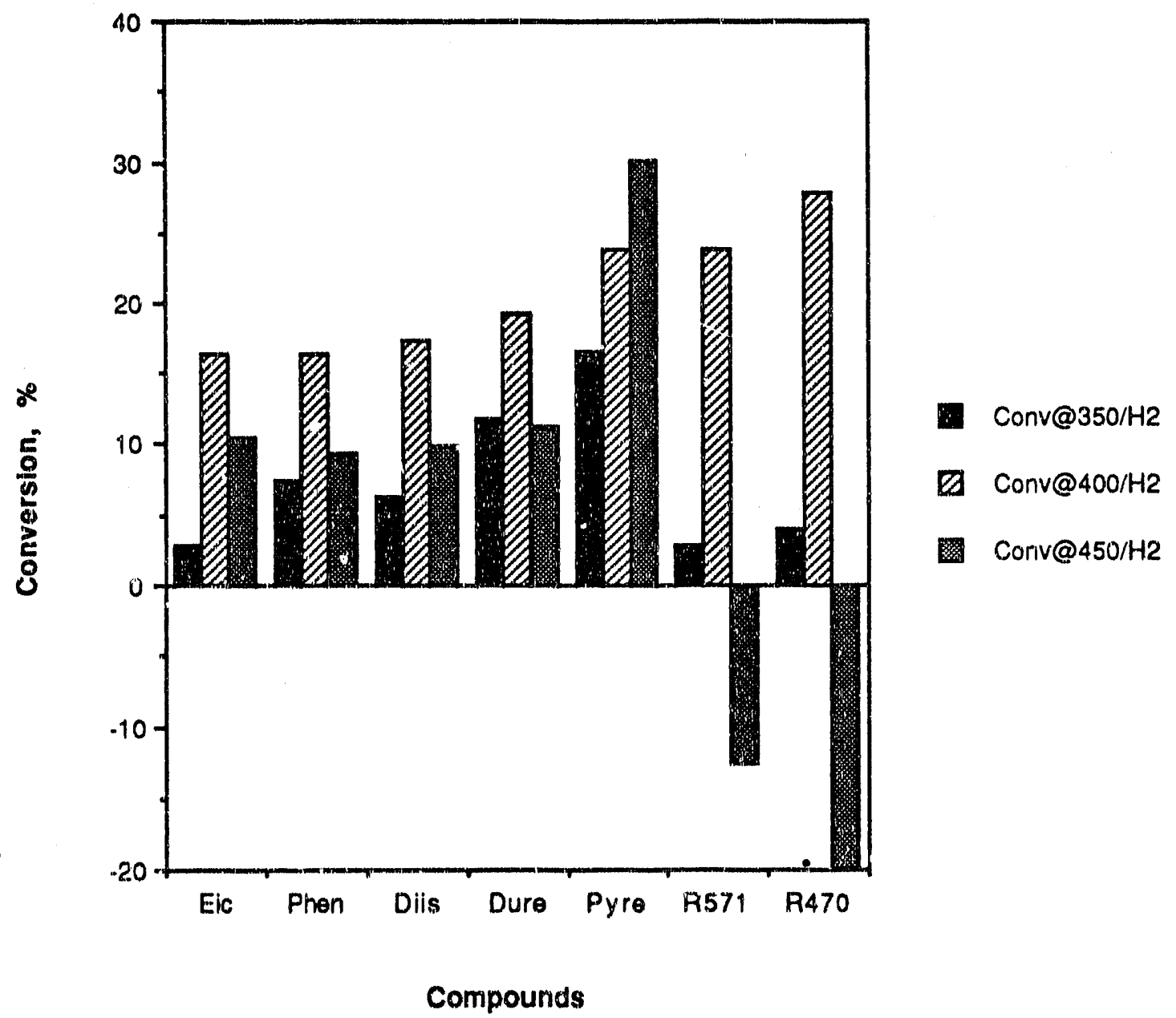

Figure 20. Conversion for PSOC1448; H2 at three reaction temperatures 


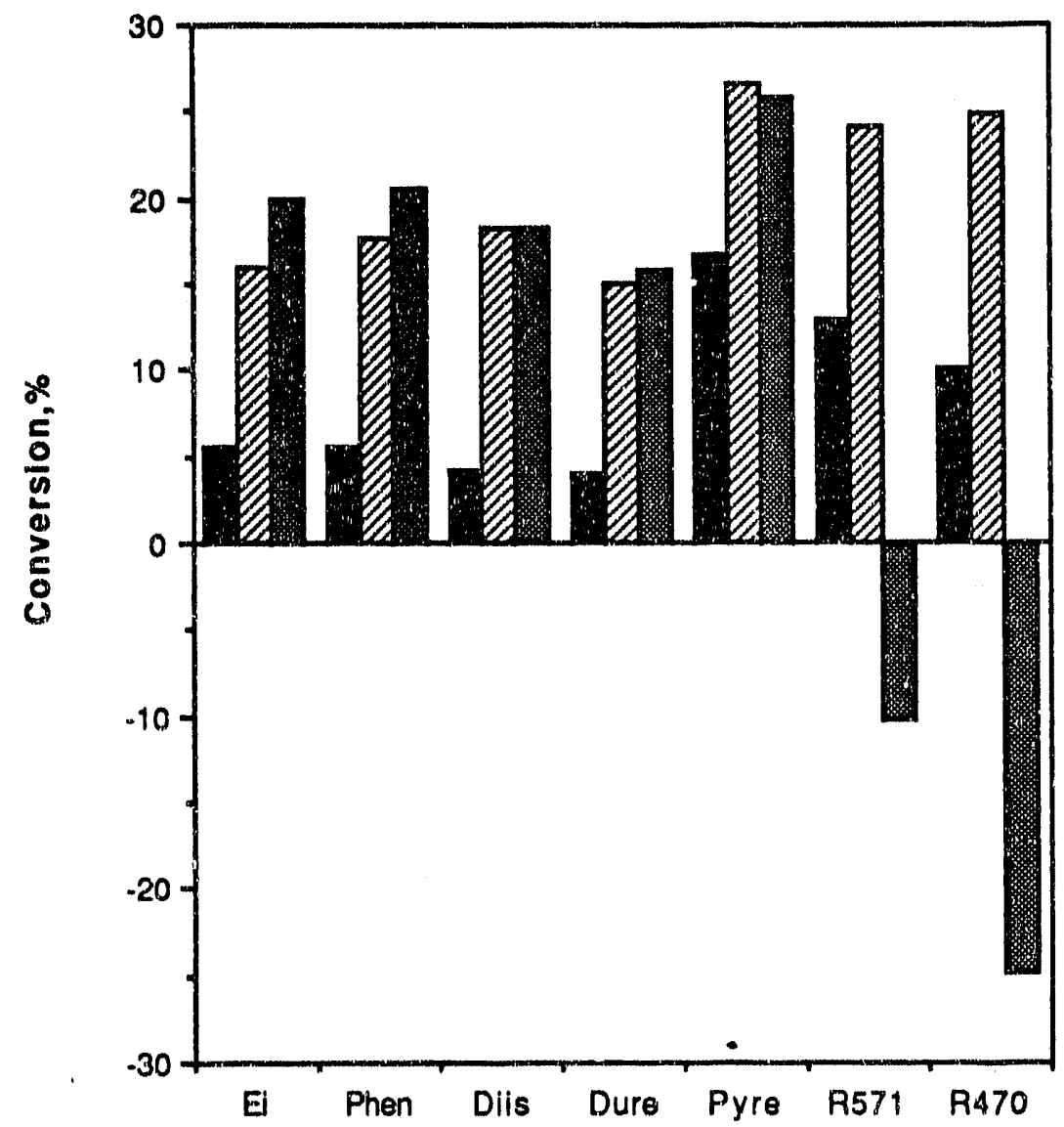

DConv@ 350

■Conv@400

图 Conv@450

Compounds

Figure 21. Conversions for PSOC1488; N2 at three reacton temperatures 


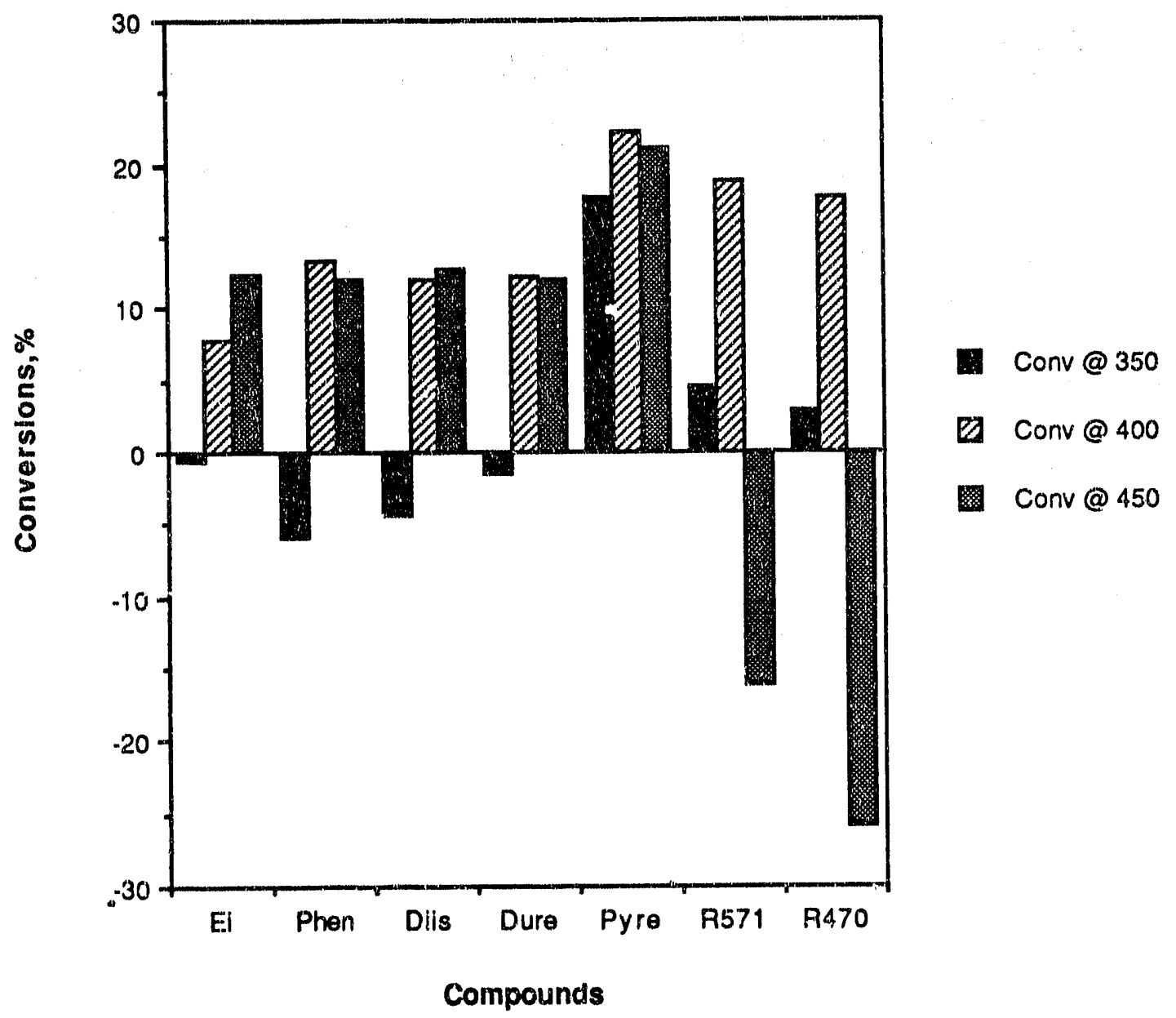

Figure 22. Conversions for PSOC1498; N2 at three reaction temperatures 


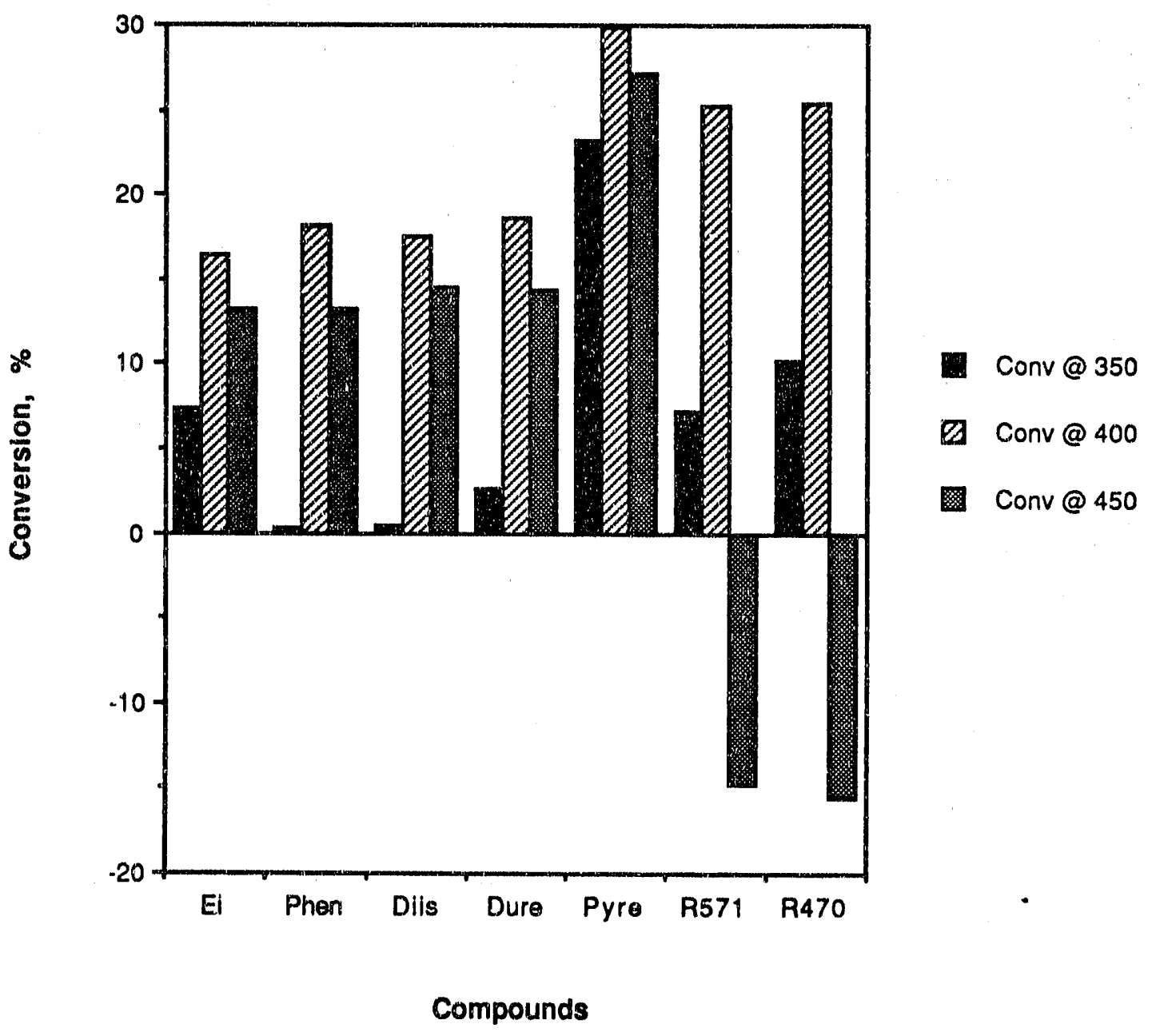

Figure 23. Conversions for PSOC1501, N2 at three reaction temperatures 


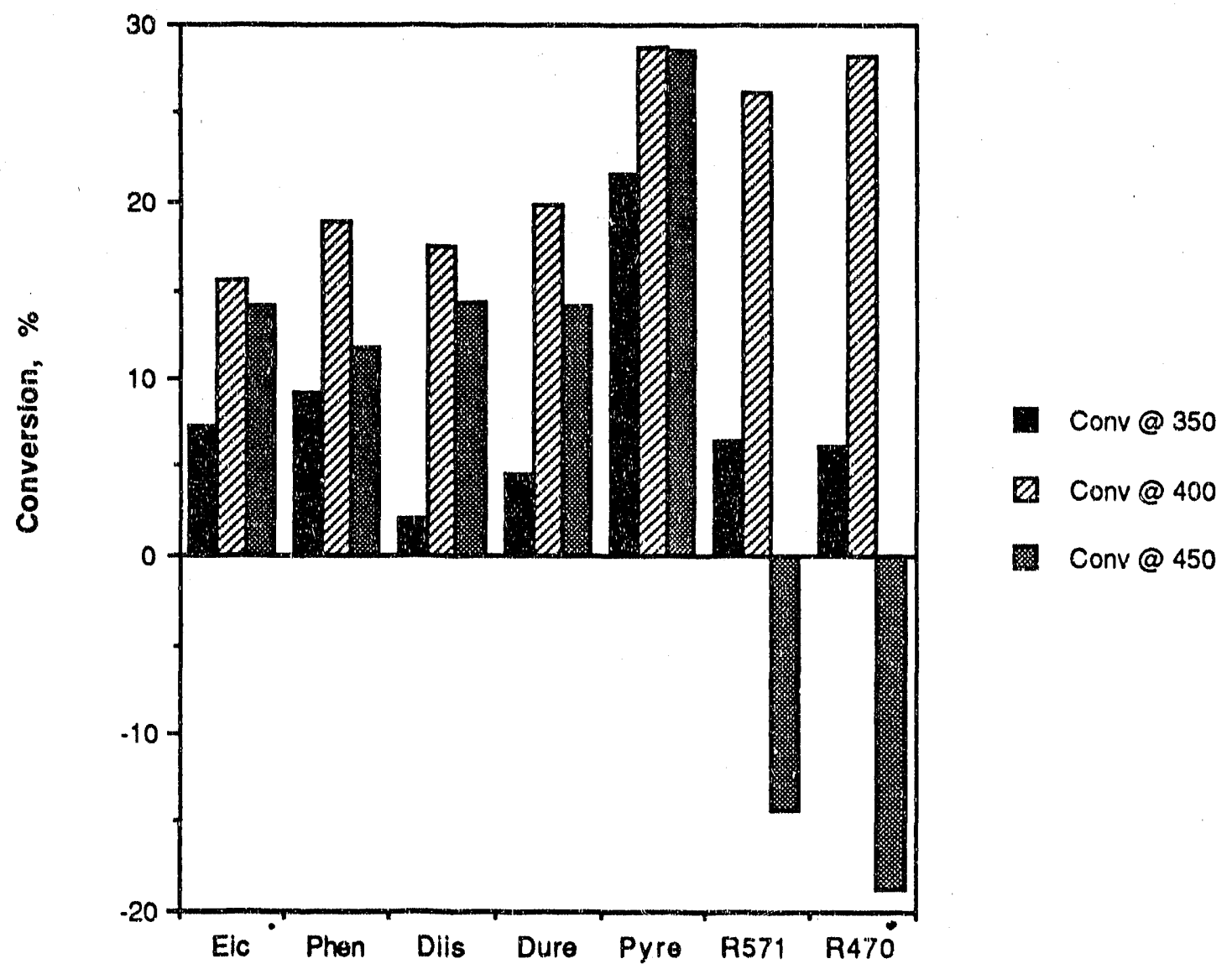

Compounds

Figure 24. Conversions for PSOC1504; N2 at three reaction temperatures 


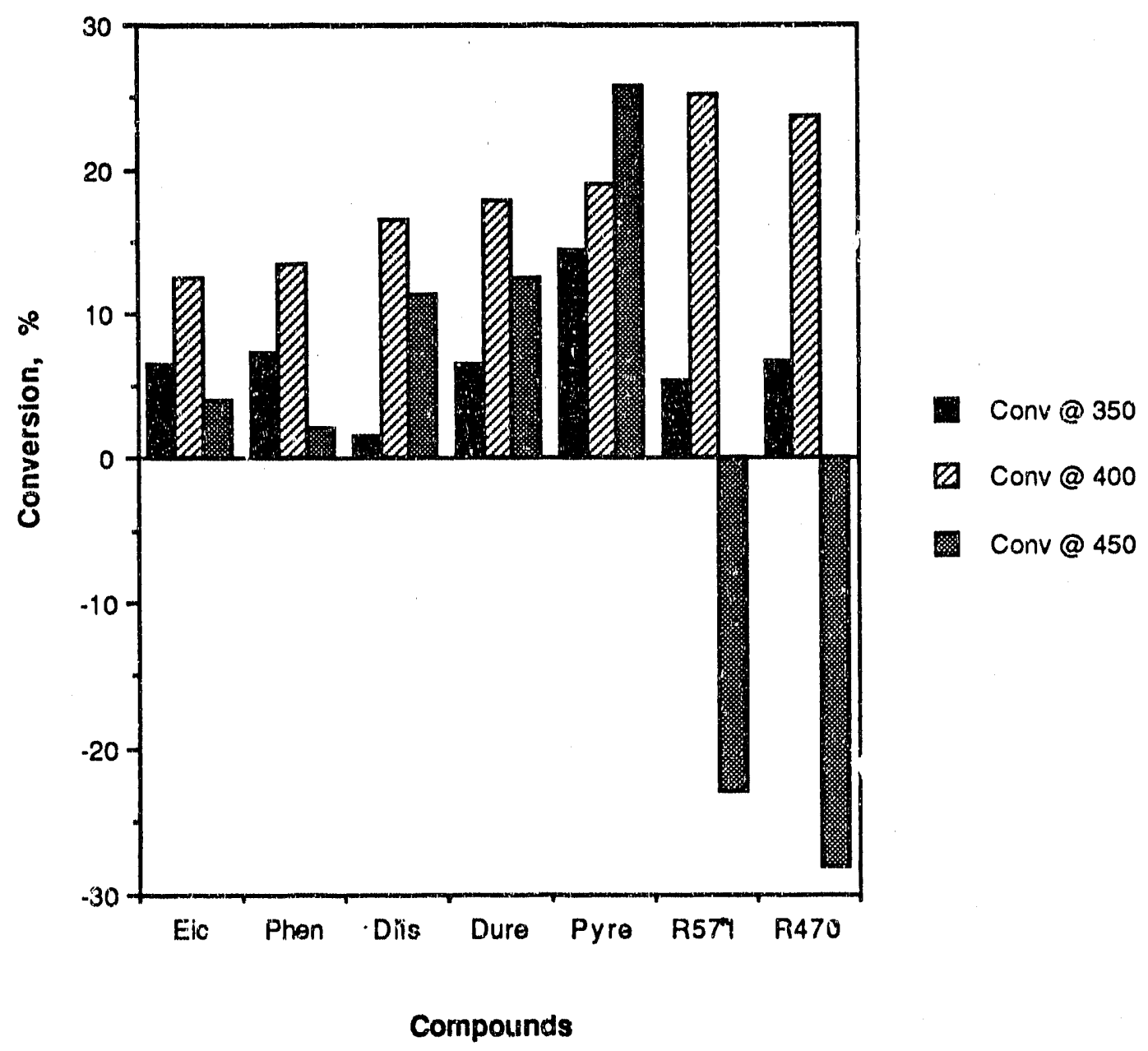

Figure 25. Conversions for PSOC1448, N2 at three reaction temperatures 
Literature Cited

[1] Schobert, H. H., J. Tomic,D. Moyer and, J. McConnie, "Inhibition of Retrogressive Reactions in Coal/Petroleum Co-Processing" U.S.D.O.E. Report, No 88PC-88935-QTR-7, 1990.

[2] Rhee, Y., J. Guin and, C. W. Curtis, Fuel Processing Technology, 22, P97, 1989. 


\section{APPENDIX 1}

This appendix contains actual data collected in the reactions of coals with five model compounds under hydrogen atmosphere and the comparisons of a vertical and horizontal design microreactor. 


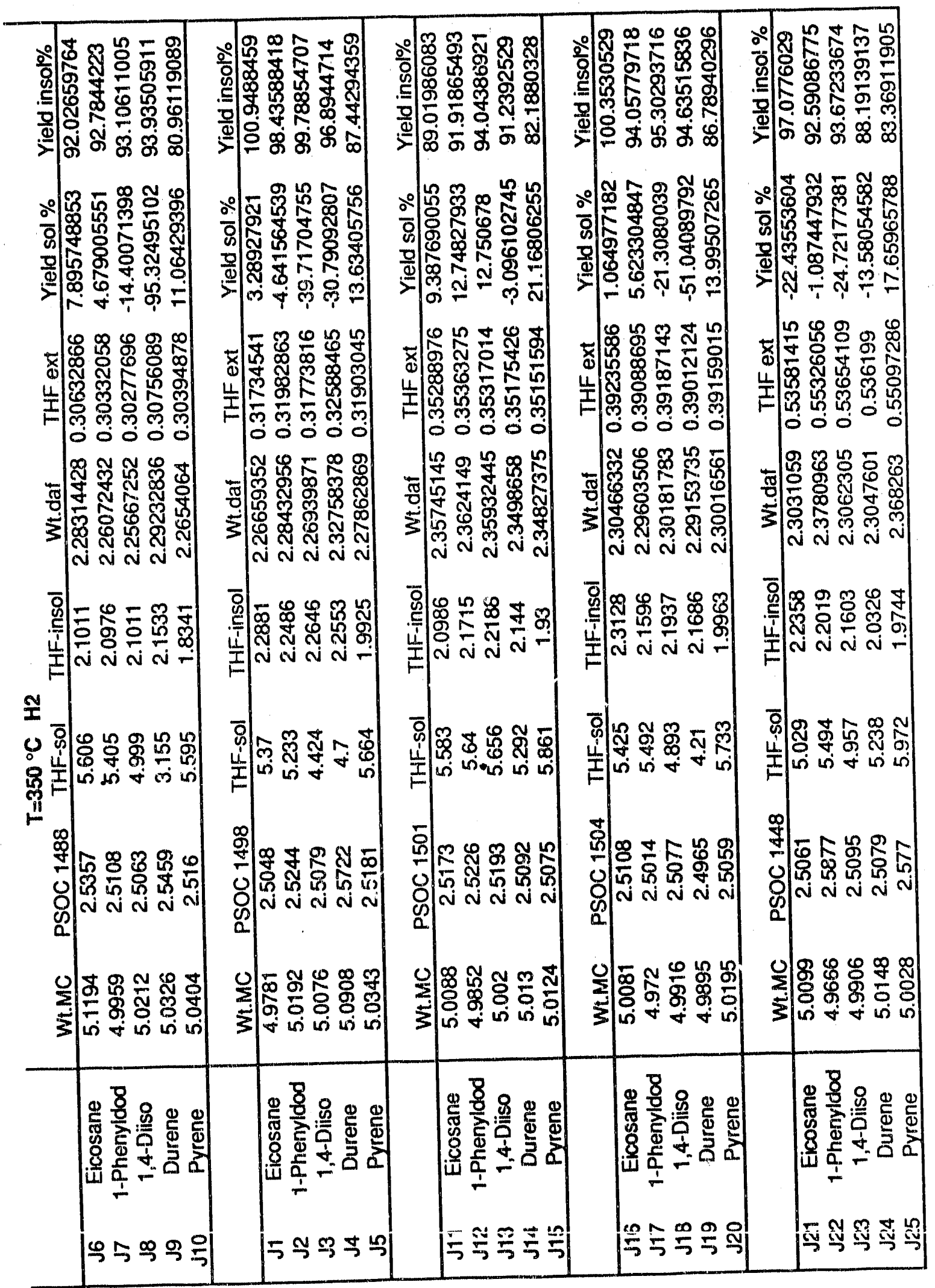




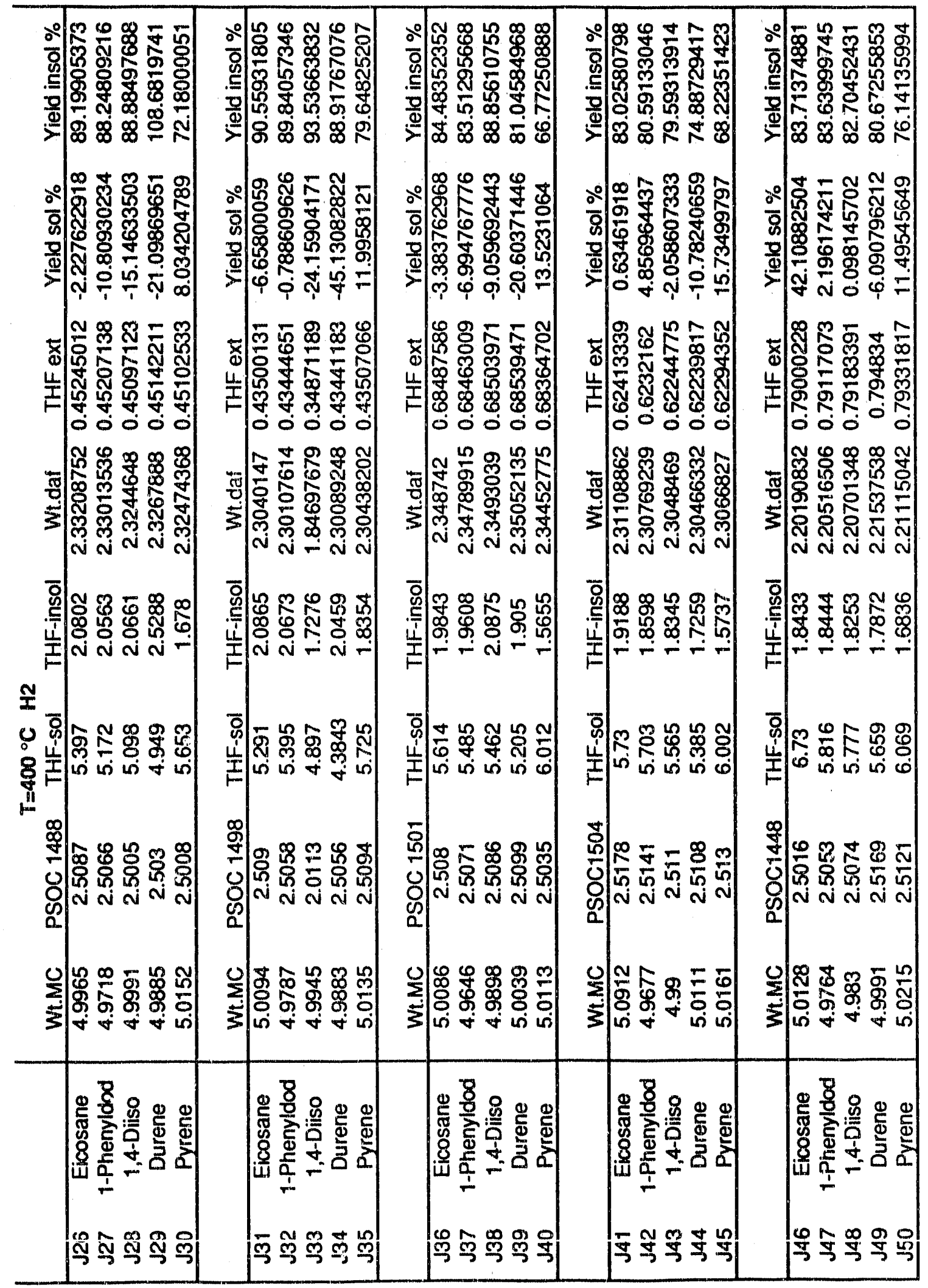




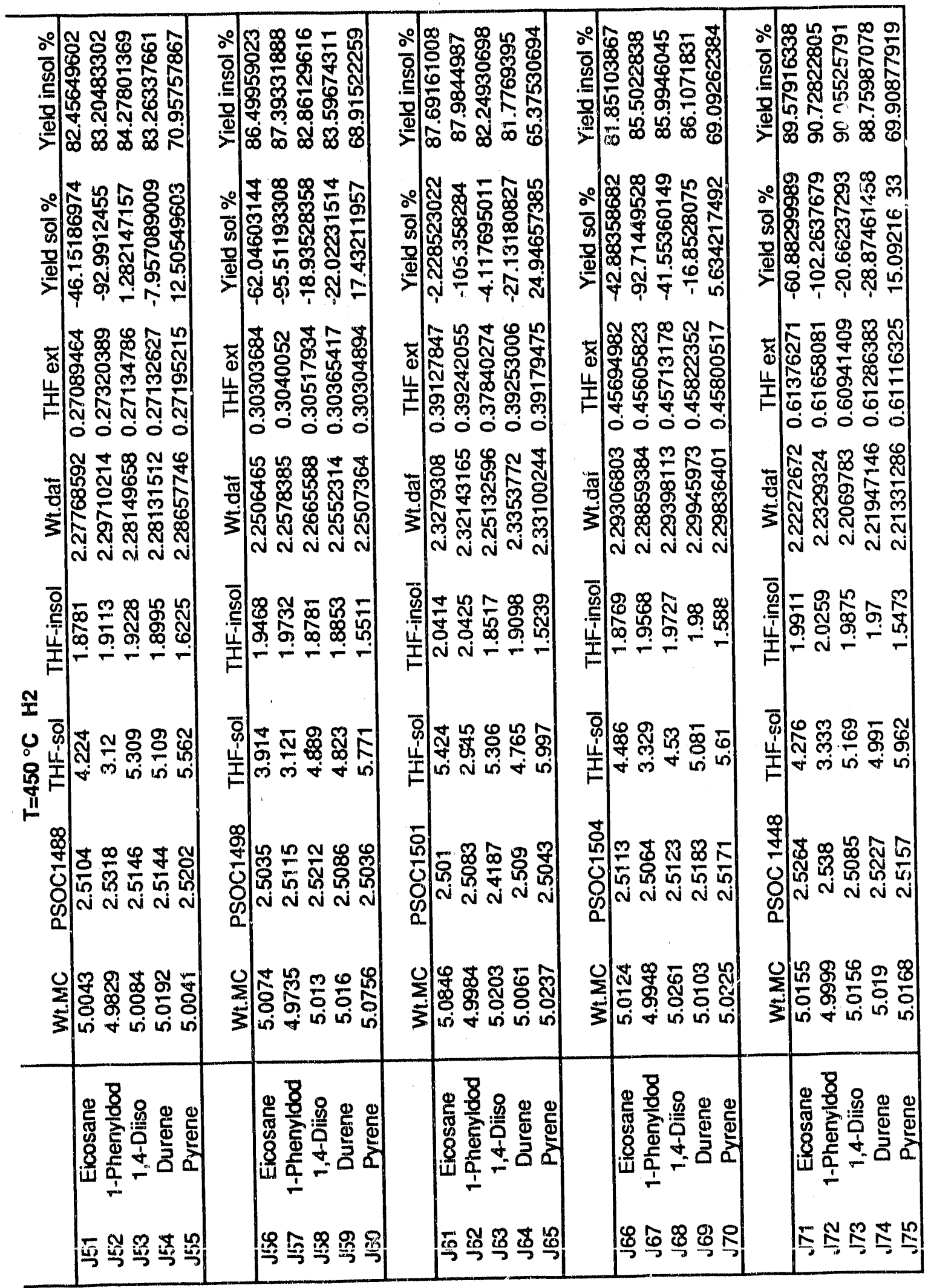




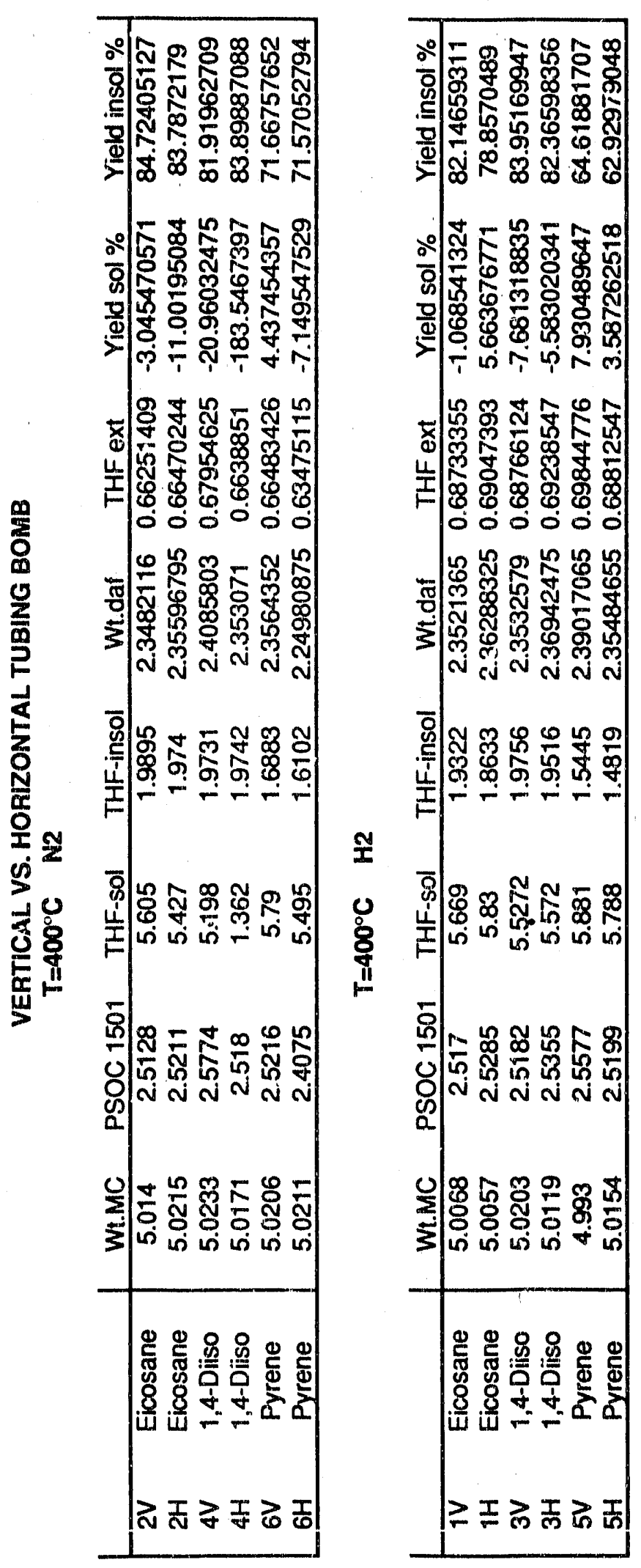




\section{APPENDIX 2}

This Appendix contains the actual data collected in thermal reactions of the resids the reactions of the coals with the two petroleum resids. 


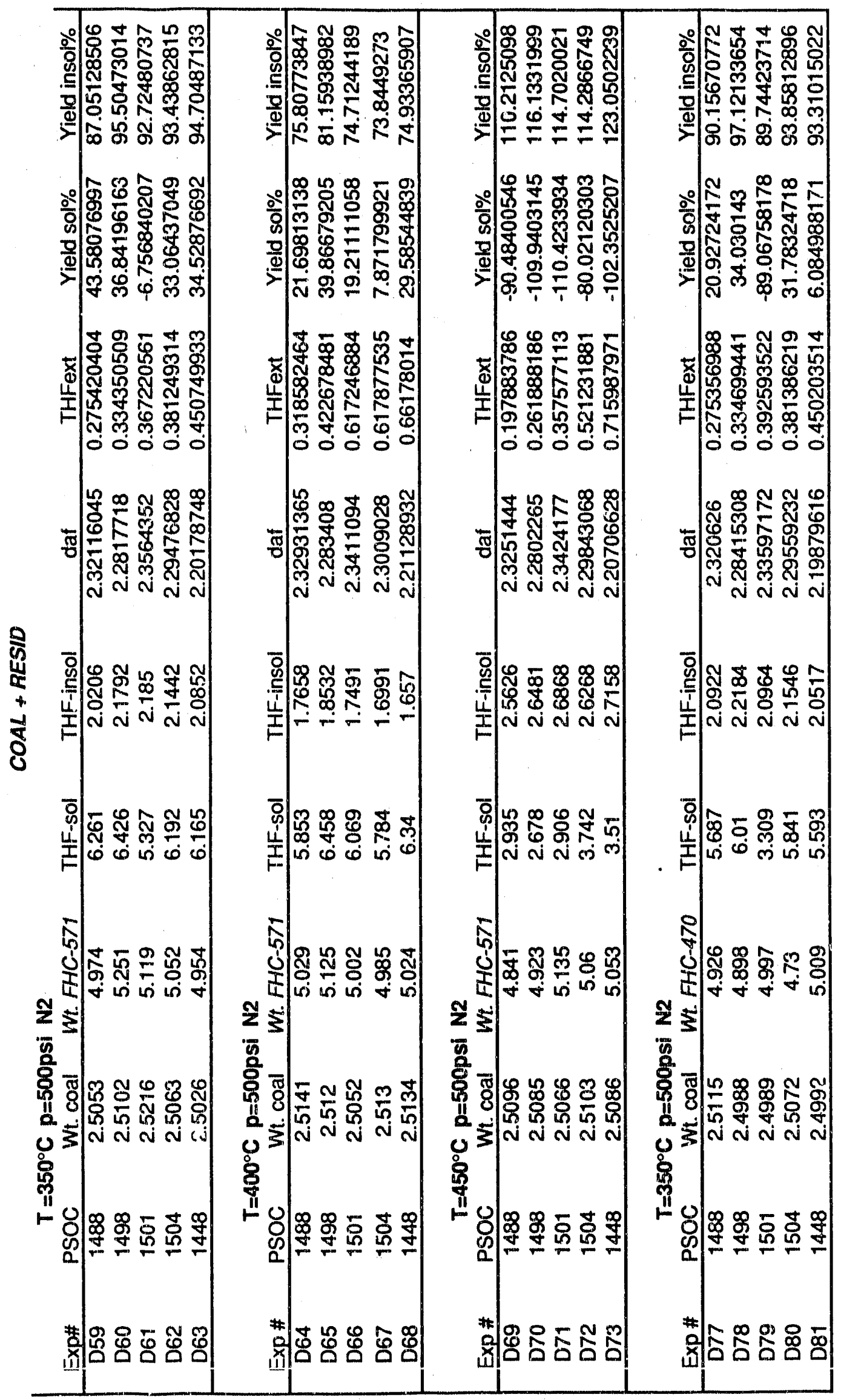




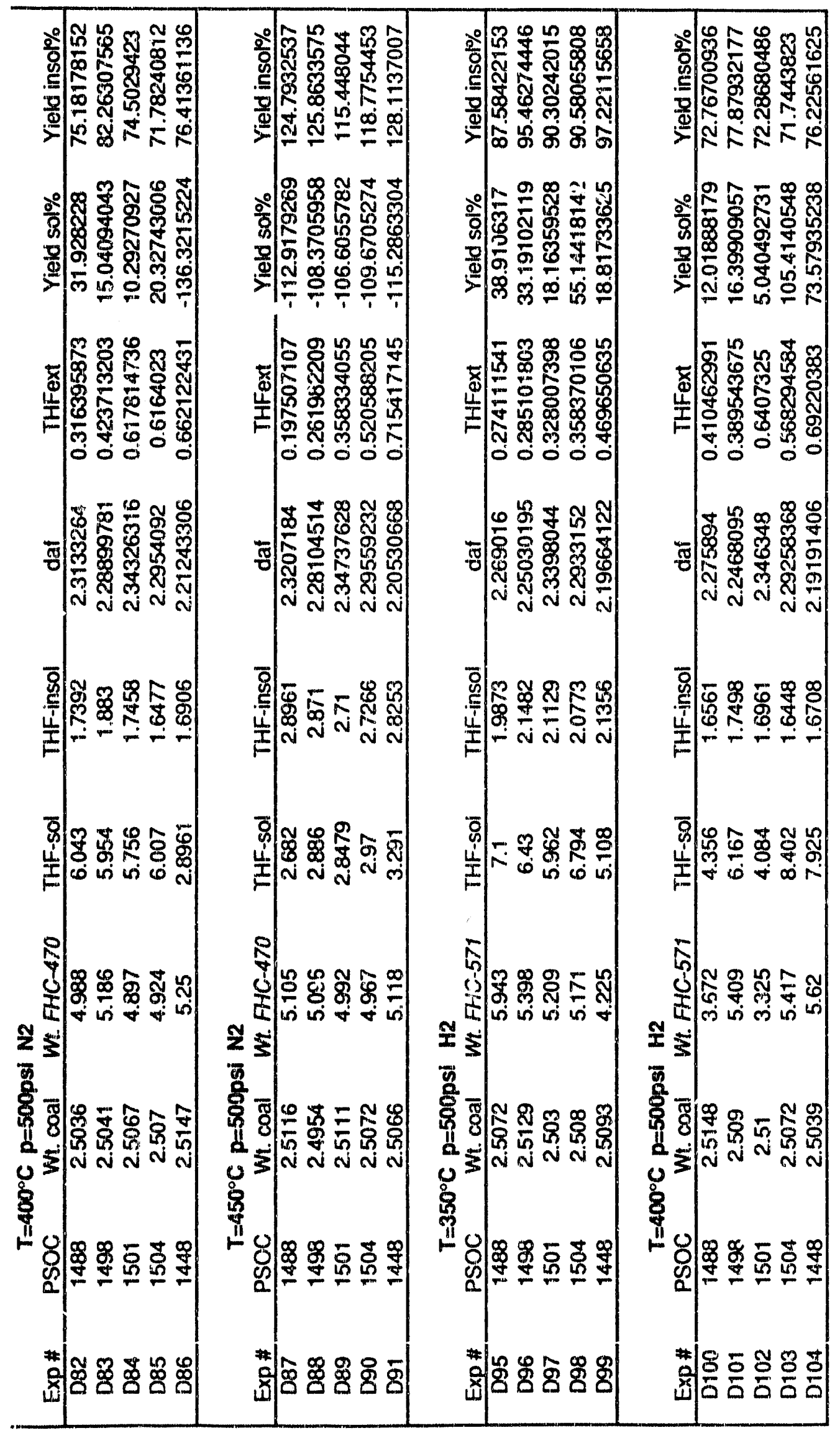




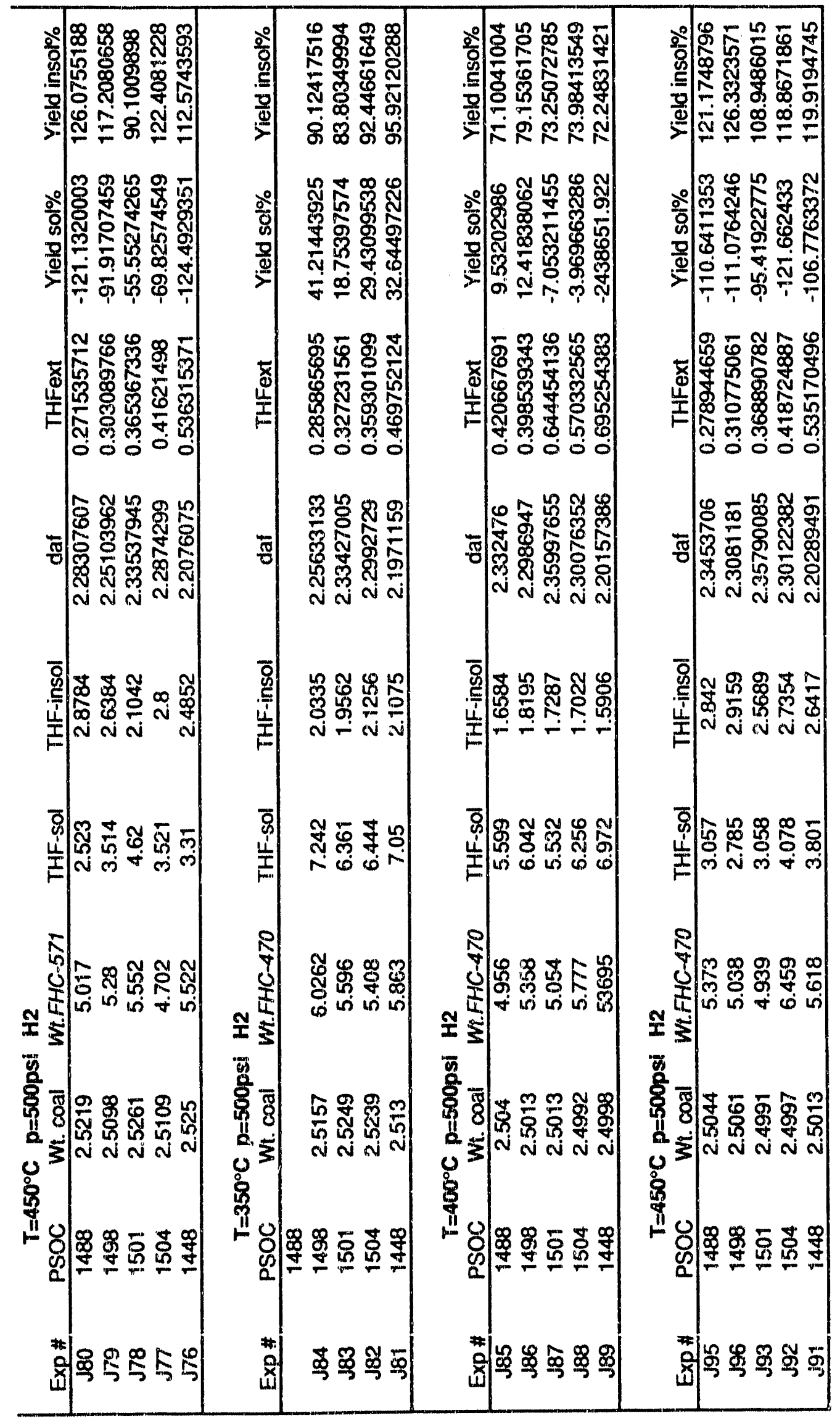


RESIDS BLANKS

\begin{tabular}{ccccc}
\multicolumn{5}{c}{ RESID S BLANKS } \\
EHC-571 P=500psi & N2 & \\
Exp\# & $T_{1}{ }^{\circ} \mathrm{C}$ & Wi. resid & THF-sol & THF-insol \\
\hline D41 & 350 & 5.387 & 5.85 & 0.003 \\
D42 & 400 & 4.066 & 3.026 & 0.004 \\
D43 & 450 & 5.223 & 4.142 & 0.1947
\end{tabular}

\begin{tabular}{ccccc}
\multicolumn{5}{c}{ FHC-470 $p=500$ psi N2 } \\
Exp \# & $\mathrm{T}_{1}{ }^{\circ} \mathrm{C}$ & Wt. resid & THF-sol & THF-insol \\
\hline D74 & 350 & 4.999 & 5.352 & 0.0033 \\
D75 & 400 & 5.015 & 5.037 & 0.0006 \\
D76 & 450 & 60271 & 3.435 & 1.0667
\end{tabular}

\begin{tabular}{|c|c|c|c|c|}
\hline \multicolumn{5}{|c|}{ FHC-571 $p=500 p s i \quad H 2$} \\
\hline Exp\# & $T^{\circ} \mathrm{C}$ & Wi. resid & THF-sol & THF-insol \\
\hline D92 & 350 & 4.78 & 5.338 & 0.0047 \\
\hline D93 & 400 & 4.906 & 5.526 & 0.0057 \\
\hline D94 & 450 & 5.276 & 4.634 & 0.139 \\
\hline \multicolumn{5}{|c|}{ FHC-470 $p=500 p s i \quad H 2$} \\
\hline Exp\# & $\mathrm{T},{ }^{\circ} \mathrm{C}$ & Wt. resid & THF-Sol & THF-insol \\
\hline 190 & 400 & 6.291 & 6.335 & 0.0095 \\
\hline J94 & 450 & 4.782 & 2.853 & 0.6613 \\
\hline
\end{tabular}


APPENDIX 3.

This appendix contains ${ }^{13} \mathrm{C}$ NMR spectra of a number of solid residues. 


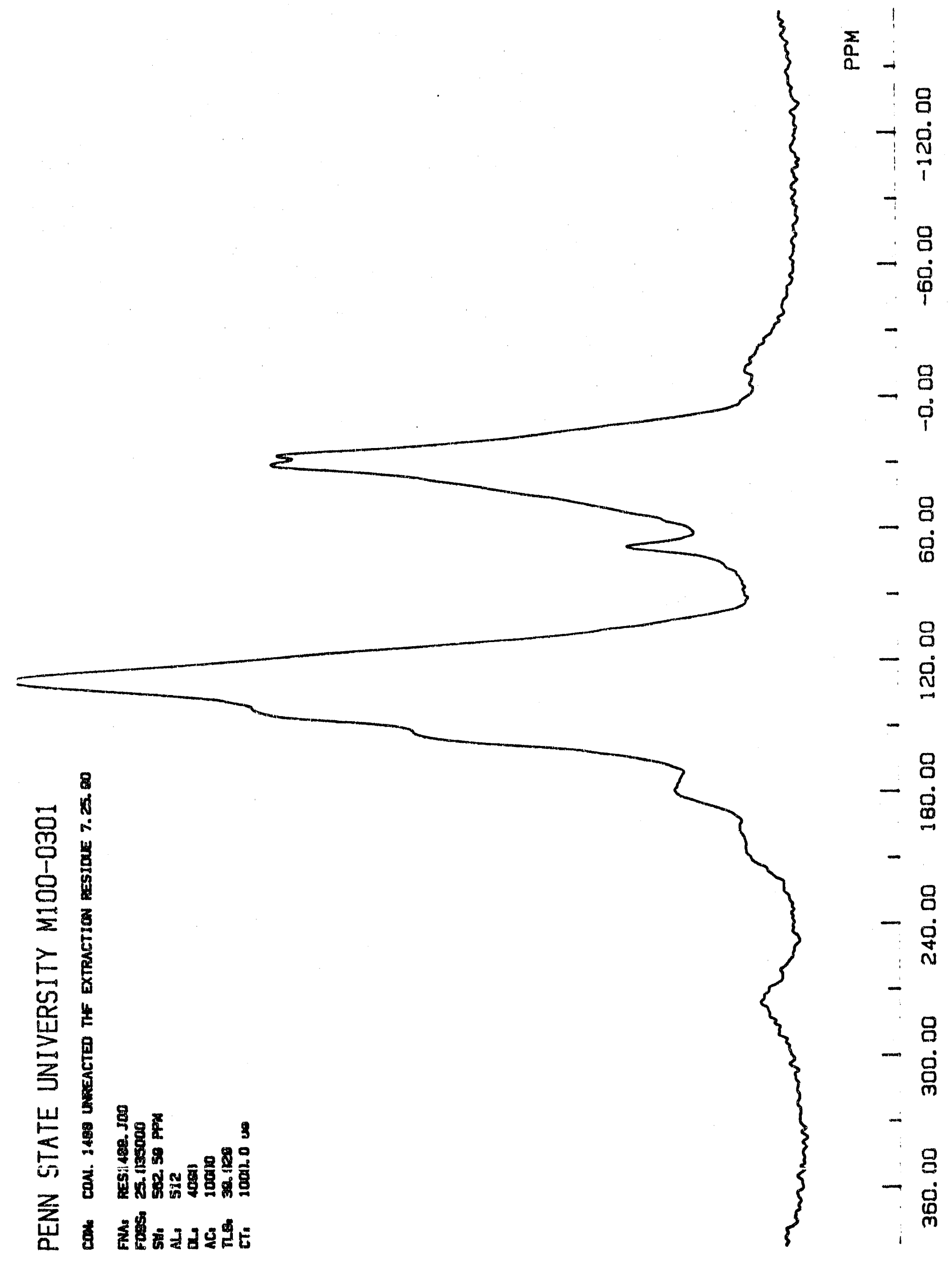



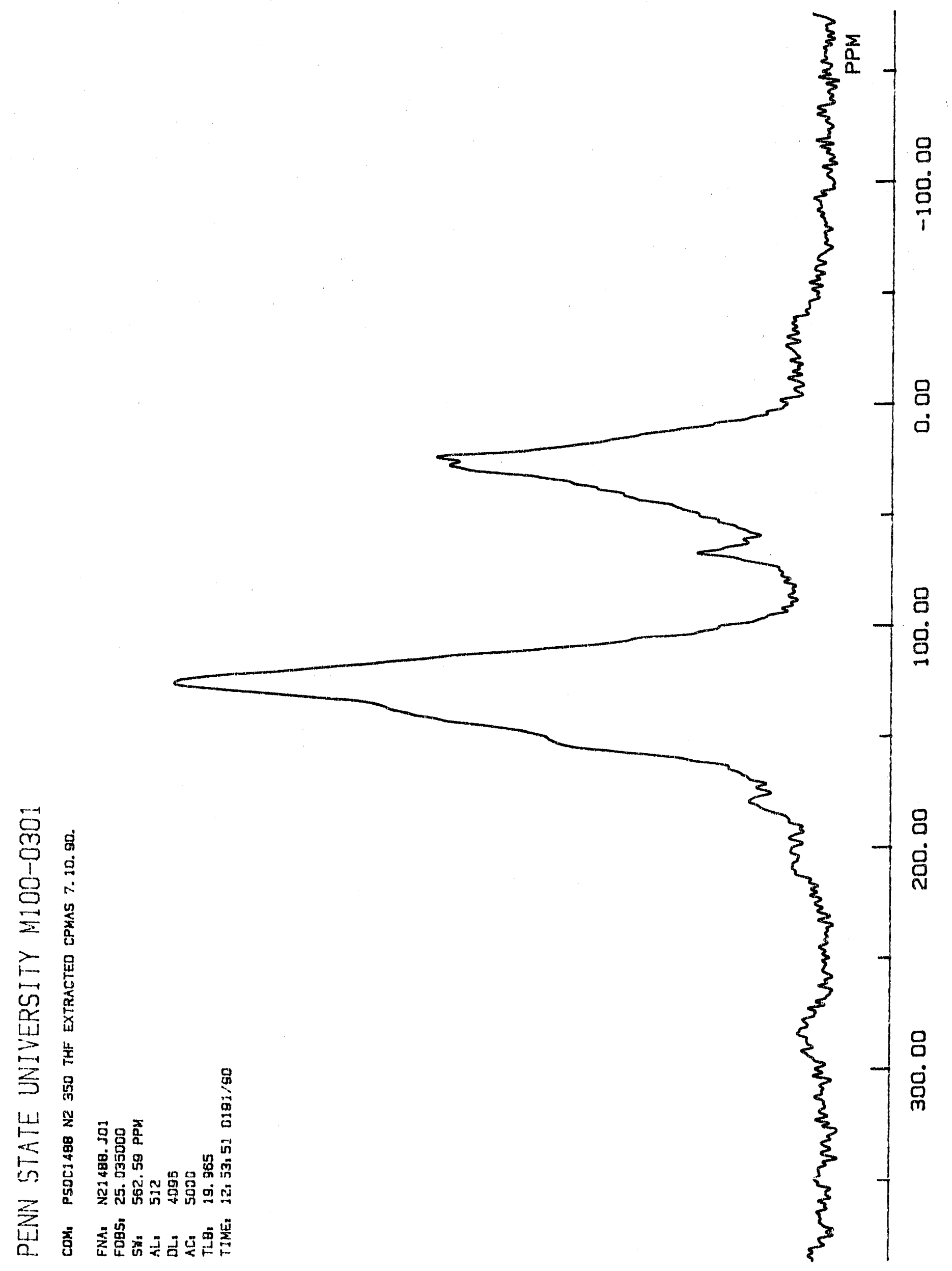

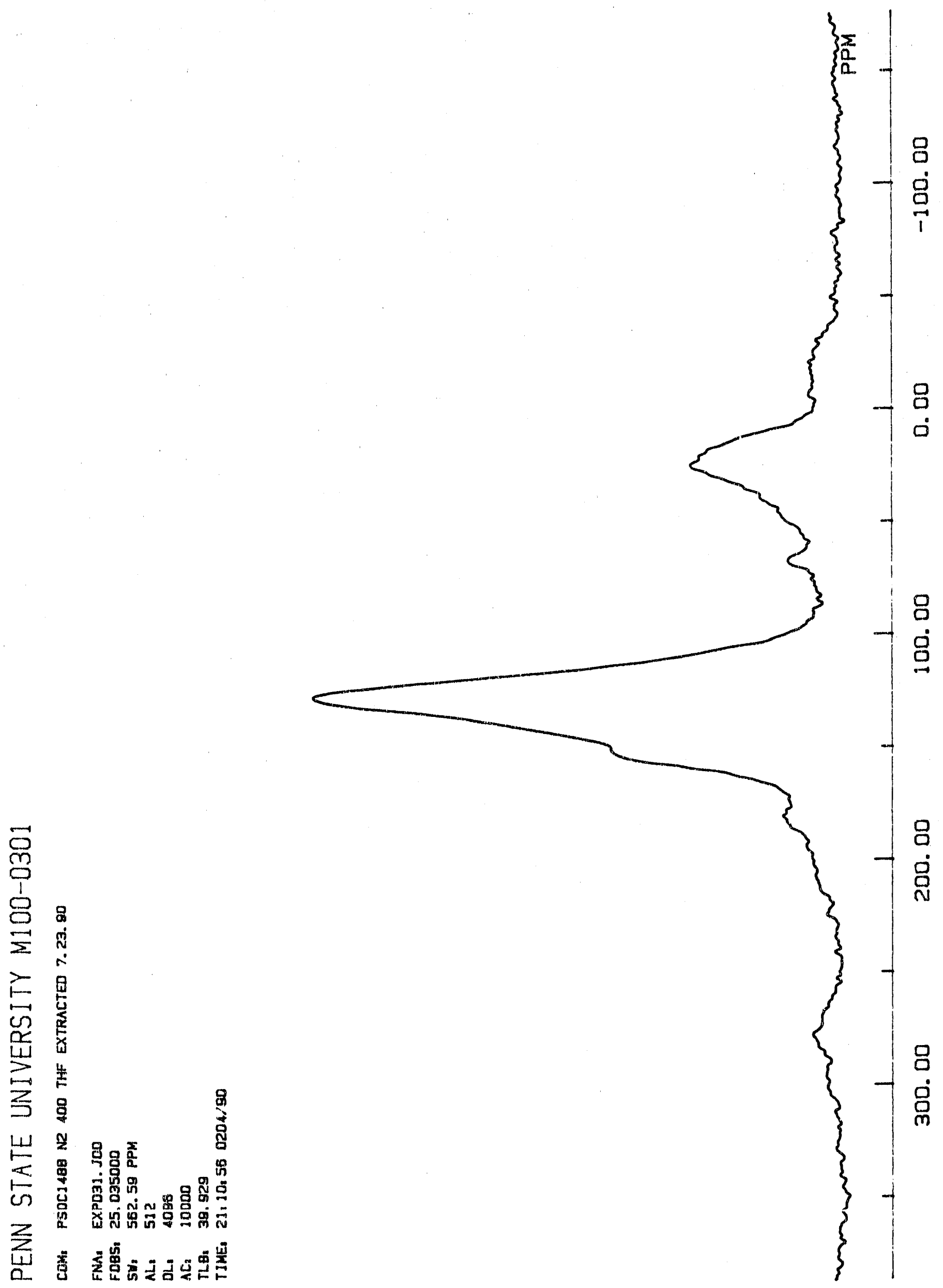

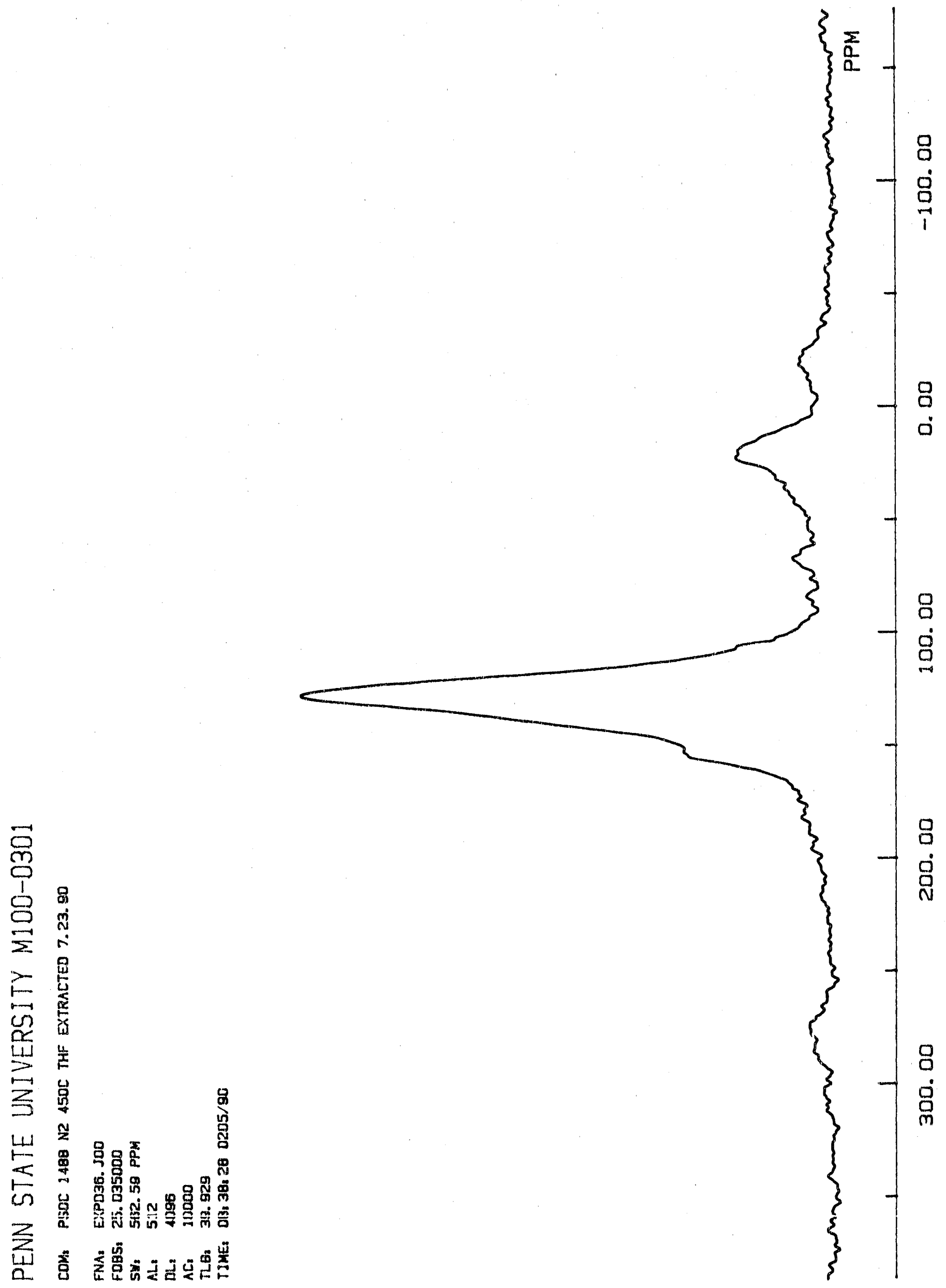


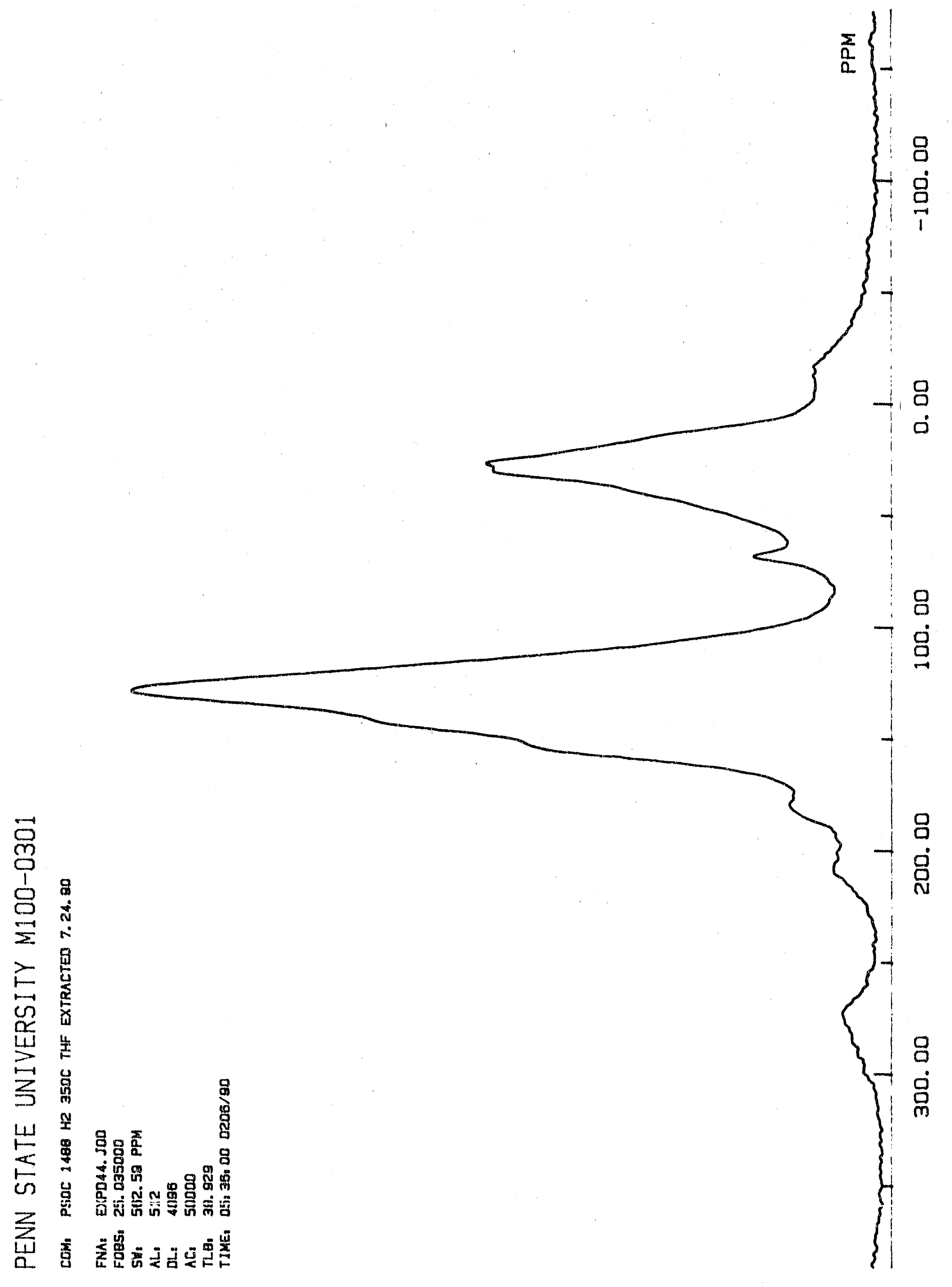



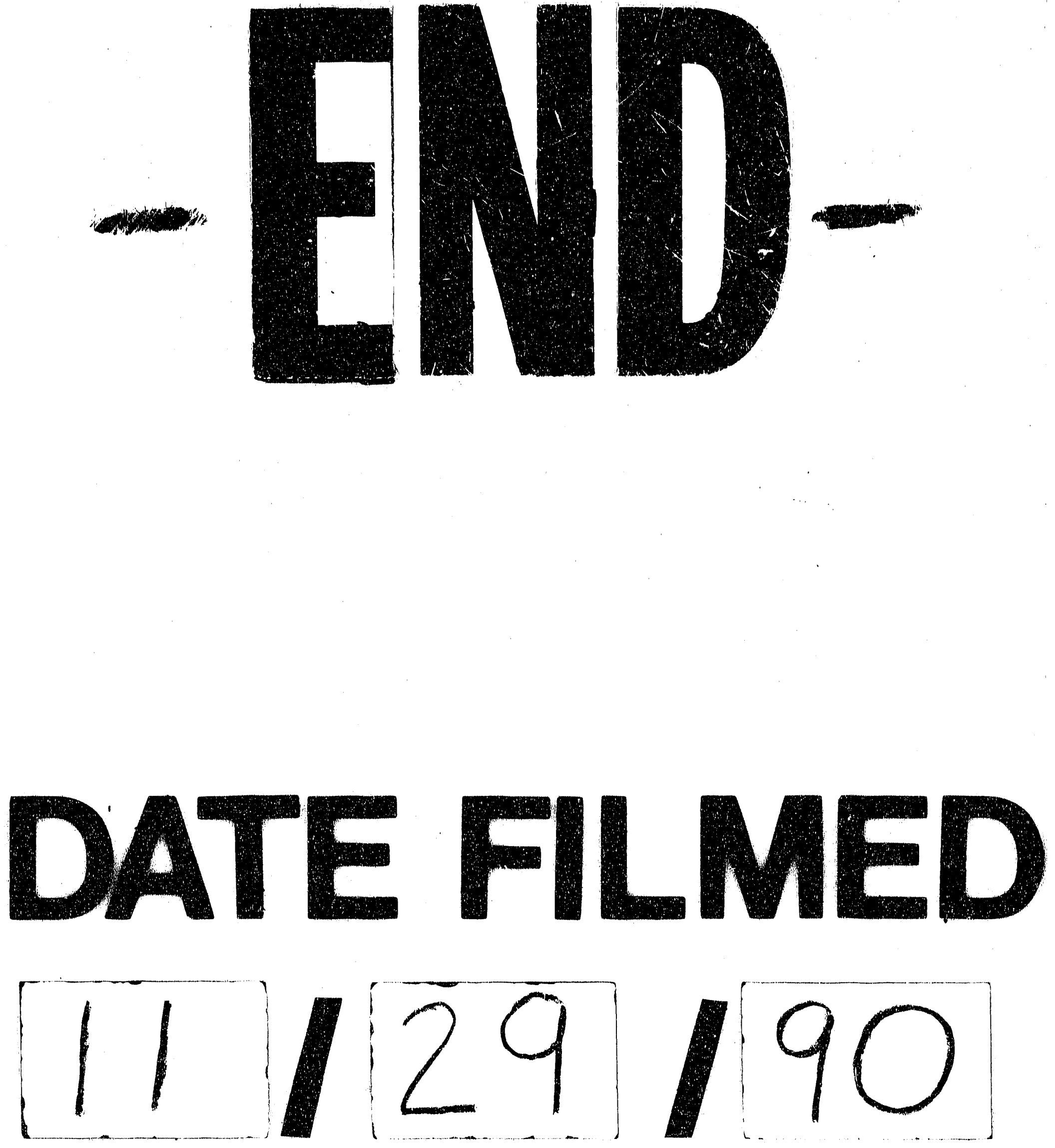
